\title{
Zonally asymmetric trends of winter total column ozone in the northern middle latitudes
}

\author{
Jiankai Zhang ${ }^{1} \cdot$ Wenshou Tian $^{1} \cdot$ Fei Xie $^{2} \cdot$ Wenjun Sang ${ }^{1} \cdot$ Dong Guo $^{3,4} \cdot$ Martyn Chipperfield $^{5} \cdot$ Wuhu Feng $^{5,6}$. \\ Dingzhu $\mathrm{Hu}^{3,4}$
}

Received: 5 February 2018 / Accepted: 7 August 2018 / Published online: 20 August 2018

(c) The Author(s) 2018

\begin{abstract}
Using various satellite-based observations, a linear ozone transport model (LOTM), a chemistry-climate model (WACCM3) and an offline chemical transport model (SLIMCAT), zonally asymmetric trends of the total column ozone (TCO) in the northern middle latitudes during winter for the period 1979-2015 are analyzed and factors responsible for the trends are diagnosed. The results reveal that there are significant negative TCO trends over the North Pacific and positive TCO trends over the northwestern North America. The zonally asymmetric TCO trends are mainly contributed by the trends in partial column ozone in the upper troposphere and lower stratosphere (UTLS) which are closely related to the long-term changes of geopotential height in the troposphere. Furthermore, the trends of geopontential height in the UTLS are mainly modulated by pattern changes in the Arctic Oscillation (AO), the Cold Ocean-Warm Land (COWL) and the North Pacific (NP) index. Accordingly, the zonally asymmetric TCO trends can be largely reconstructed by the trends of the above three teleconnection patterns. Sea surface temperature (SST) changes over the Pacific Ocean and the Atlantic Ocean can also exert a significant contribution to the zonally asymmetric TCO trends through their influence on the COWL and NP patterns. In addition, chemical ozone loss partially offsets the positive trends in zonal TCO anomalies over Central Siberia and enhances the positive TCO trends over northwestern North America. However, the contribution of chemical processes to the zonally asymmetric TCO trends is relatively smaller than that of dynamical transport effects. Interpreting the zonally asymmetric TCO trends and their responsible factors would be helpful for accurately predicting the stratospheric ozone return date in the northern middle latitudes.
\end{abstract}

Wenshou Tian

wstian@1zu.edu.cn

1 Key Laboratory for Semi-Arid Climate Change of the Ministry of Education, College of Atmospheric Sciences, Lanzhou University, Lanzhou, China

2 State Key Laboratory of Earth Surface Processes and Resource Ecology, College of Global Change and Earth System Science, Beijing Normal University, Beijing, China

3 School of Atmospheric Sciences, Nanjing University of Information Science and Technology, Nanjing, China

4 Key Laboratory of Meteorological Disasters of China Ministry of Education/Joint International Research Laboratory of Climate and Environment Change/Collaborative Innovation Center on Forecast and Evaluation of Meteorological Disasters, Nanjing University of Information Science and Technology, Nanjing, China

5 School of Earth and Environment, University of Leeds, Leeds, UK

6 National Center for Atmospheric Science, School of Earth and Environment, University of Leeds, Leeds, UK

\section{Introduction}

The implementation of the Montreal Protocol and its amendments has effectively stopped the continuous stratospheric ozone depletion caused by anthropogenic ozone depleting substances, and global TCO is expected to show a positive trend in the coming decades (e.g. Newchurch et al. 2003; Angell and Free 2009; Eyring et al. 2010; Krzyścin 2010; Zhang et al. 2014; Chipperfield et al. 2017). However, some studies have shown that stratospheric ozone concentrations over different regions along the same latitude exhibit different recovery rates. Over some regions, TCO even continues to decrease due to changes in local dynamical and chemical processes (Hood and Soukharev 2005; Zhang et al. 2014, 2018; Wargan et al. 2018), suggesting that long-term ozone variations are highly longitude-dependent. Previous studies pointed out that the trends in the deviation of ozone from the zonal mean over some regions can reach and even exceed the zonal mean ozone trend at that latitude, particularly at 
northern middle latitudes (e.g. Niu et al. 1992; Hood and Zaff 1995; Peters and Entzian 1999). Therefore, the zonal asymmetric ozone (ZAO) trends at northern middle latitudes both in the past and future deserve much attention.

Previous studies have shown that ZAO variations can result in different climate variability (e.g. Kirchner and Peters 2003; Peters et al. 2015) compared to zonally symmetric ozone variations. In many long-term General Circulation Model simulations, a prescribed time series of zonal mean ozone is employed (Cagnazzo et al. 2006; Cionni et al. 2011; Szopa et al. 2013; Gonzalez et al. 2014; Xie et al. 2016, 2017) and the ZAO heating effects, which have an important contribution to chemical-radiative-dynamical feedbacks (e.g. Sassi et al. 2005; Nathan and Cordero 2007; Gabriel et al. 2007, 2013; McCormack et al. 2011; Peters et al. 2015), are not properly considered. Previous modeling studies (e.g. Gabriel et al. 2007; Crook et al. 2008; Waugh et al. 2009) have provided some evidence that numerical simulation with $\mathrm{ZAO}$ variations can produce a colder winter polar stratosphere in the Southern hemisphere and a warmer winter for the northern polar region, which is closer to observation than that without ZAO variations. Gillett et al. (2009) found that ZAO variations could lead to up to $4 \mathrm{~K}$ temperature changes in the lower stratosphere, suggesting that the inclusion of ZAO variations in climate models may be essential for better simulation of stratospheric temperature trends. Some previous studies have investigated the decadal ZAO variations during the significant ozone depletion period, i.e., the pre-2000 period (e.g. Niu et al. 1992; Hood and Zaff 1995; Peters et al. 1996; Peters and Entzian 1999). However, the ZAO variations after 2000, when the TCO over most places began to recover, are not very well studied and the factors responsible for the ZAO trend are still not well understood.

In the subpolar region, regional TCO anomalies caused by displacement of the stratospheric polar vortex may significantly affect the ZAO structure (James et al. 2000; Calisesi et al. 2001; Vigliarolo et al. 2005). However, the TCO anomalies resulting from the polar vortex shift are often observed over Eurasia in winter rather than at all longitudes (Zhang et al. 2018), suggesting that other factors may also affect ZAO variations. Peters and Entzian (1999) showed that there exists a close link between $\mathrm{ZAO}$ variations and geopotential height variations at $300 \mathrm{hPa}$ on decadal time scales. The 300-hPa geopotential height is generally a good indicator of large-scale wave structure in the middle and upper troposphere. Therefore, it is likely that interannual variations and trends in ZAO are related to changes in planetary waves. Indeed, many previous studies have demonstrated the important role of planetary waves in modulating ZAO variations (e.g. Peters and Entzian 1999; Peters et al. 2008; Efstathiou et al. 2003; Hio and Yoden 2004; Grytsai et al. 2005; Gabriel et al. 2011; Ialongo et al. 2012; Zhang et al. 2015) and have proposed that the planetary waves of tropospheric origin could affect TCO through tropopause height modulations and stratosphere-troposphere exchange processes. Nevertheless, whether and to what extent planetary wave changes exert an influence on the zonally asymmetric TCO trend in the past 30 years remains unclear.

In the present study, we will analyze ZAO variations over the past three decades and diagnose the relative importance of various processes which dominate the zonally asymmetric TCO trend over the whole northern middle latitudes during winter (December-January-February, DJF) when the ZAO structure is more pronounced (Hood and Zaff 1995; Gabriel et al. 2011). Data and methods are described in Sect. 2. In Sect. 3, the ZAO trend and the factors responsible for this trend are examined and discussed. The role of tropospheric processes in influencing ZAO trend is analyzed in Sect. 4, followed by a summary and discussions in Sect. 5 .

\section{Data and methods}

The National Institute of Water and Atmospheric Research (NIWA v3.3) $\left(1^{\circ}\right.$ latitude $\times 1.25^{\circ}$ longitude) TCO data used here, obtained from http://www.bodekerscientific.com/data/ total-column-ozone, is publically available for the period 1979-2015. The dataset combines satellite-based ozone measurements from four Total Ozone Mapping Spectrometer (TOMS) instruments, three different retrievals from the global ozone monitoring experiment (GOME) instruments, data from four solar backscatter ultra-violet (SBUV) instruments and data from the ozone monitoring instrument (OMI). More details about the dataset can be found in Bodeker et al. (2005), Müller et al. (2008) and Struthers et al. (2009). The TCO and ozone profile derived from the European Centre for Medium Range Weather Forecasts (ECMWF) Interim (http://www.ecmwf.int, Dee et al. 2011; Dragani 2011) and National Aeronautics and Space Administration-Modern Era Retrospective Analysis for Research and Applications (NASA-MERRA) (https://gmao.gsfc. nasa.gov/reanalysis/MERRA, Rienecker et al. 2011) are also employed for the period 1979-2015. Although there are uncertainties on the order within $20 \%$ for the ozone in the extratropical lower stratosphere, some other studies showed that the ERA-Interim ozone field agrees reasonably well with independent observations and performs better than the earlier ERA-40 reanalysis (Dragani 2011; Škerlak et al. 2014; Guo et al. 2017). For more details please see Dragani (2011). In this paper, the departure of TCO at a given location from its corresponding zonal mean is referred to as the 'zonal anomaly' and is used to represent the ZAO structure. The December-January-February (DJF) mean in one year 
is calculated by the December value this year and the values of January and February next year.

To analyze the influence of planetary wave changes on TCO, a linear ozone transport model (hereafter, 'LOTM', unless otherwise stated) described in Hood and Zaff (1995) is used. The chemical continuity equation for ozone is shown as

$\frac{d r}{d t}=P-L$,

where $r$ is the ozone mixing ratio, $P$ is the photochemical ozone production rate, $L$ is the chemical ozone loss rate and $\frac{d}{d t}=\frac{\partial}{\partial t}+\vec{v} \cdot \nabla$. In the wintertime lower stratosphere, photochemical processes are much slower than dynamic processes and ozone transport related to large-scale atmospheric circulations is more important, i.e. photochemistry can be neglected compared with dynamical advection in generating ozone variations. Since the ZAO structure in the northern middle latitudes is more pronounced than the meridional asymmetric ozone structure, the Eq. (1) reduces to

$\bar{u} r_{x}^{\prime}+v^{\prime} \overline{r_{y}}+w^{\prime} \overline{r_{z}}=0$

where, subscripts $x, y, z$ denote the zonal, meridional and vertical derivative, respectively. $\bar{u}$ is the zonal mean of the zonal wind component, $r_{x}^{\prime}$ is the zonal derivative of the zonal anomaly of mixing ratio, $v^{\prime}$ and $w^{\prime}$ are zonal anomalies of meridional and vertical velocities, $\overline{r_{y}}$ and $\overline{r_{z}}$ are meridional and vertical derivatives of the zonal mean of ozone mixing ratio. Assuming geostrophic balance, the zonal anomaly of meridional velocity can be represented as a function of zonal anomaly of geopotential height $Z^{\prime}$ by

$v^{\prime}=\frac{g_{0} Z_{x}^{\prime}}{f}$,

where $g_{0}$ is the mean value of the local acceleration of gravity $(g)$ at sea level, and $f$ is the Coriolis parameter. The zonal anomaly of vertical velocity $w^{\prime}$ can be written in form of the adiabatically thermodynamic energy equation as

$w^{\prime}=\frac{g_{0}}{N^{2}}\left(\overline{u_{z}} Z_{x}^{\prime}-\bar{u} Z_{z x}^{\prime}\right)$,

where $N^{2}$ is the buoyancy frequency squared. Substituting (3) and (4) into (2) yields

$r_{x}^{\prime}=-\frac{g_{0}}{\bar{u}}\left[\left(\frac{\overline{r_{y}}}{f}\right) Z_{x}^{\prime}+\left(\frac{\overline{r_{z}}}{N^{2}}\right)\left(\overline{u_{z}} Z_{x}^{\prime}-\bar{u} Z_{z x}^{\prime}\right)\right]$.

Equation (5) describes the zonal anomaly of ozone mixing ratio as a function of geopotential height and zonal mean of the zonal wind. Given that the three dimensional (3D) distribution of the geopotential height anomaly $Z^{\prime}$, the zonal mean wind $\bar{u}$ and the distribution of mean ozone mixing ratio $\bar{r}$ are known, then the zonal anomaly of ozone $r_{x}^{\prime}$ can be calculated. More details about the LOTM can be found in Hood and Zaff (1995). The DJF mean of geopotential height and the climatological mean of ozone field, the inputs of LOTM, are derived from ERA-Interim data with a resolution of $1^{\circ}$ latitude $\times 1^{\circ}$ longitude from 1979 to 2015.

In this study, the contributions of climate variabilities to the ZAO trend are analyzed. The monthly Arctic Oscillation (AO) and Pacific-North American (PNA) index used here are downloaded from http://www.cpc.ncep.noaa.gov/ products/precip/CWlink/daily_ao_index/ao_index.html and ftp://ftp.cpc.ncep.noaa.gov/wd52dg/data/indices/pna_index .tim, respectively. The monthly cold ocean-warm land (COWL) index is defined as the weighted average of DJF mean $1000-500 \mathrm{hPa}$ thickness north of $40^{\circ} \mathrm{N}$, with a positive and uniform weight over the land as well as a negative and uniform weight over the ocean ( $\mathrm{Lu}$ et al. 2004). The North Pacific (NP) Index is the area-weighted sea level pressure over the region $30^{\circ}-65^{\circ} \mathrm{N}, 160^{\circ} \mathrm{E}-140^{\circ} \mathrm{W}$ (Trenberth and Hurrell 1994).

Moreover, a set of three simulations conducted by the Whole Atmosphere Community Climate Model, version 3 (WACCM3; Garcia et al. 2007), including the control experiment $\mathbf{R 0}$ and two sensitivity experiments $\mathbf{R} \mathbf{1}$ and $\mathbf{R 2}$, were performed in order to clarify the specific roles of sea surface temperature (SST) variations and ozone-depleting substances (ODSs) changes in the northern mid-latitude ZAO trends. The WACCM3 has 66 vertical levels extending from the ground to $145 \mathrm{~km}$, and the model's vertical resolution is $1.1-1.4 \mathrm{~km}$ in the lower stratosphere. WACCM3 has been extensively evaluated against various satellite datasets and performs well in simulating the stratospheric chemistry and dynamics (e.g. Eyring et al. 2006). Details of the model can be found in Garcia et al. (2007). These three simulations were performed at a resolution of $1.9^{\circ}$ latitude $\times 2.5^{\circ}$ longitude, with interactive chemistry enabled. The control experiment R0 driven by all time-varying external forcings represents the simulation of the transient atmospheric evolution in the past 30 years. In the run Ro, the time-varying monthly values of greenhouse gas emissions and mixing ratio lower boundary conditions of ODSs are specified following the datasets used in Garcia et al. (2007). Meanwhile, the monthly mean time-varying observed SST and sea ice distributions are derived from the Hadley Centre reconstruction (Rayner et al. 2003). The two sensitivity simulations are the same in all aspects as the configurations of $\mathbf{R 0}$ except that the SST in R1 and the ODSs in $\mathbf{R} 2$ use their monthly climatologies for the period 1979-2005. The comparison between $\mathbf{R 0}$ and $\mathbf{R} \mathbf{1}$ is to identify the influence of time-varying SST on ZAO trends in the northern middle latitudes, whereas the difference between $\mathbf{R 0}$ and $\mathbf{R 2}$ is to investigate the impact of ODSs on ozone trend. The three simulations 
were run for 30 years with the first 3 years excluded for the model 'spin-up' and the remaining 27 years of data are used for analysis.

Because the LOTM does not include chemical processes and the ozone simulation in free-running version of WACCM depends on the simulation of wind that is largely different from realistic wind, here we further use the SLIMCAT offline 3D chemical transport model (Chipperfield 2006) to clarify the role of chemical processes in the formation of ZAO trend. The model is driven by horizontal winds and temperature from the reanalysis data of the ECMWFInterim (Dee et al. 2011). The SLIMCAT long-term simulations (1979-2015) performed in this study have a coarse horizontal resolution of about $5.625^{\circ}$ latitude $\times 5.625^{\circ}$ longitude and 32 levels from the surface to $60 \mathrm{~km}$. The model uses a hybrid $\sigma-p$ vertical coordinate (Chipperfield 2006) with detailed stratospheric chemistry. Vertical advection is calculated from the divergence of the horizontal mass flux (Chipperfield 2006), and chemical tracers are advected, conserving second-order moments (Prather 1986). The SLIMCAT simulation initializes a 'passive odd-oxygen' tracer that is set equal to the modeled chemical $\mathrm{O}_{x}$ concentration on 1st December every year for the Northern Hemisphere and then advected passively without chemistry. At any point and time after 1st December, the difference between this passive $\mathrm{O}_{x}$ and the model's chemically integrated $\mathrm{O}_{x}$ is the net chemical $\mathrm{O}_{x}$ change in air which has been advected to the point (Feng et al. 2005). $\mathrm{O}_{x}$ is mainly $\mathrm{O}_{3}$ below $30 \mathrm{~km}$, especially in winter when there is no sunlight in the polar region. Hereafter, the chemical $\mathrm{O}_{x}$ change is called as 'chemical ozone' change.

\section{Zonally asymmetric ozone trend and its influencing factors}

Figure 1 shows the linear trends in DJF mean TCO and zonal TCO anomalies from different data sets. NIWA observations during 1979-2015 (Fig. 1a) indicate evident TCO negative trends over the North Pacific, East Asia, Caspian Sea and the northwestern Atlantic Ocean; whereas the TCO decreasing trends over the northeastern Pacific, northwestern North America, the southwestern Atlantic Ocean, Europe and Central Siberia $\left(45^{\circ}-60^{\circ} \mathrm{N}, 85^{\circ}-120^{\circ} \mathrm{E}\right)$ are weak and even reversed over some regions. Similar features in TCO trends in the northern middle latitudes can be also found in Frossard et al. (2013) which separated the TCO trend attributed to ODSs from that due to dynamical variabilities. The above features are more noticeable in the linear trend map of TCO anomalies with zonal mean removed (Fig. 1b), highlighting the longitude dependence of TCO trends. In addition, the positive and negative centers of ZAO trends constitute a somewhat zonal wave- 3 structure with three positive centers over northwestern North America, southern Atlantic Ocean and Central Siberia (Fig. 1b). The trends of TCO and zonal TCO anomalies derived from ERA-Interim and MERRA reanalysis data (Fig. 1c-f) are similar to the NIWA observations, suggesting that the results in our study are not sensitive to reanalysis system. Interestingly, the linear trend map of zonal TCO anomalies in the SLIMCAT simulation (Fig. 1h) is similar to that derived from NIWA and ERA-Interim data, although the negative TCO trends over middle latitudes from the SLIMCAT simulation are stronger than those in other datasets (Fig. 1g), implying that the ZAO trend is independent of the zonal mean of TCO trend.

The spatial distribution of the ZAO trends derived from the ERA-Interim, MERRA and SLIMCAT data sets also consists of three positive and three negative centers (Fig. 1d, $\mathrm{f}, \mathrm{h}$ ), consistent with that in NIWA observations (Fig. 1b). Particularly note that the trends in partial column ozone between 70 and $300 \mathrm{hPa}$ derived from ERA-Interim and MERRA reanalysis data and the SLIMCAT simulation (Fig. 2a-c) appear to dominate the zonally asymmetric TCO trends (Fig. 1d, f, h) and the simulated partial ozone column trends in the UTLS by the LOTM (Fig. 2d) shows a similar pattern with the ZAO trends in the UTLS derived from ERA-Interim data, with a spatial correlation coefficient of 0.85 . It is worth pointing out that the modeled ozone by LOTM is merely a function of geopotential height, implying that the changes of the geopotential height field in the UTLS and the associated large-scale dynamic processes play a crucial role in the ZAO trends. Ozone variations in the mid- and upper stratosphere only play a minor role in the zonally asymmetric TCO trends (not shown), although the LOTM cannot well capture the ozone trends in these layers where ozone photochemistry has an important effect on the ozone concentrations.

WMO (2011) reported that mid-latitude TCO shows a weak recovery signal after the mid-1990s due to the steadily decreasing ODSs in response to the implementation of the Montreal Protocol and its amendments. We select the year 1997 as the turnaround year of the TCO time series (Yang et al. 2006). The piecewise linear trends of TCO and zonal TCO anomalies for the period 1979-1997 (referred to as 'ozone depletion' period) and 1997-2015 (referred to as 'ozone recovery' period) are shown in Fig. 3. During the 'ozone depletion' period (Fig. 3a), TCO decreases at different rates in different regions, although the TCO over the whole middle latitudes show negative trends, as reported by previous studies (e.g. Callis et al. 1997; Hadjinicolaou et al. 2005; Hood and Soukharev 2005). The maximum negative TCO trend occurs over East Asia and the TCO decline over northwestern North America is weak, as is more evident in the linear trends of the zonal TCO anomalies (Fig. 3c). During the 'ozone recovery' period (Fig. 3b), TCO over 
Fig. 1 a, c, e, $\mathbf{g}$ Linear trends of December-January-February (DJF) mean of total column ozone (TCO) derived from a NIWA data, $\mathbf{c}$ ERA-Interim and e MERRA reanalysis data as well as $\mathbf{g}$ SLIMCAT simulation for the period 1979-2015. b, d, $\mathbf{f}, \mathbf{h}$ are the same as $\mathbf{a}, \mathbf{c}, \mathbf{e ,}, \mathbf{g}$, but for zonal TCO anomalies (see Sect. 2 for details). The linear trends over the dotted regions are statistically significant at the $90 \%$ confidence level according to the Student's $t$ test (a) NIWA TCO

(b) NIWA TCOanom

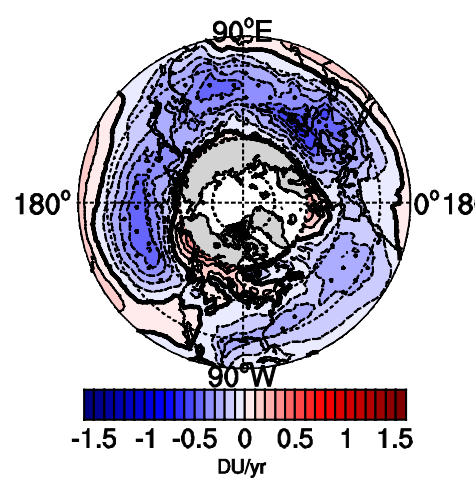

(c) Interim TCO

(d) Interim TCOanom
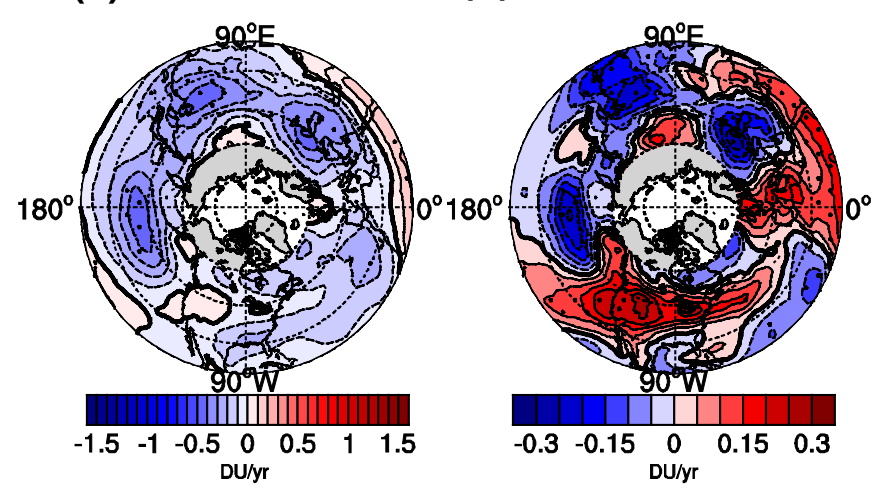

(e) MERRA TCO

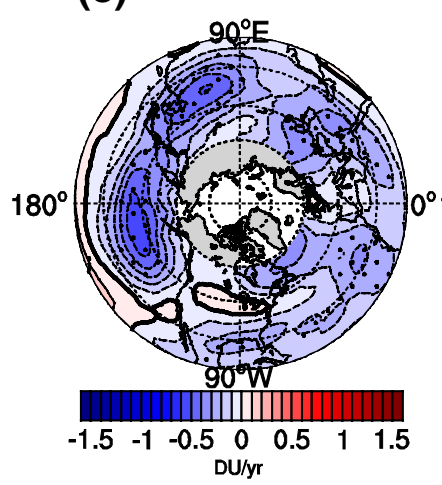

(g) SLIMCAT TCO

(f) MERRA TCOanom

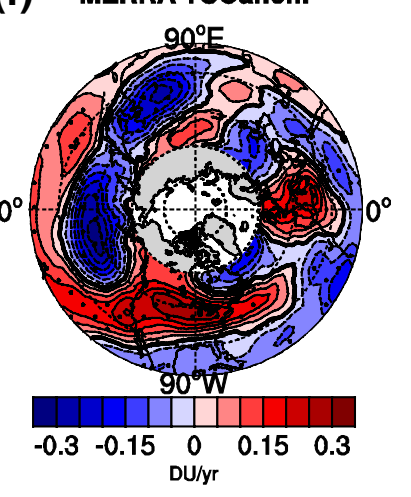

(h) SLIMCAT TCOanom

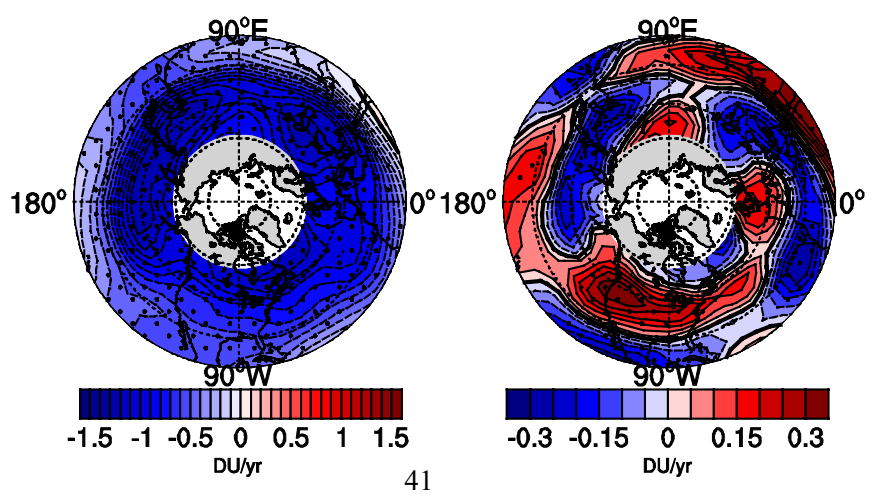


Fig. 2 Linear trends of zonal anomalies of DJF mean ozone column between 70 and $300 \mathrm{hPa}$ for the period 1979-2015 derived from a ERA-Interim reanalysis data, b MERRA reanalysis data, c SLIMCAT simulation and d LOTM simulation (see Sect. 2 for details). The linear trends over the dotted regions are statistically significant at the $90 \%$ confidence level according to the Student's $t$ test (a) Interim $70-300 \mathrm{hPa} \mathrm{O3}$

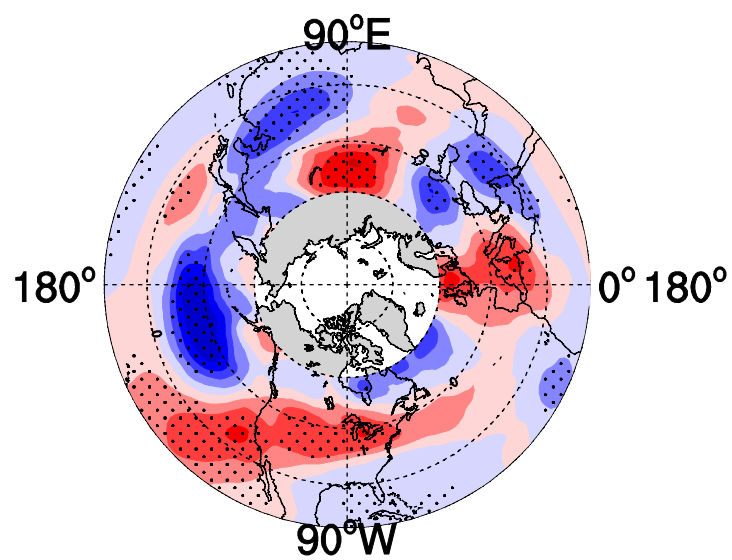

(b) MERRA 70-300hPa 03

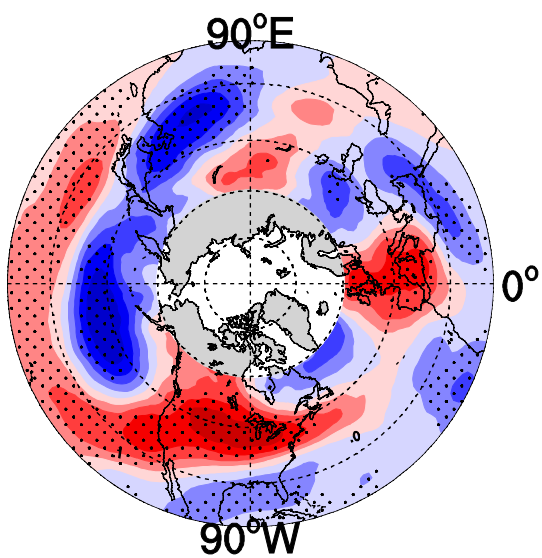

(d) Dyn-Model 70-300hPa 03

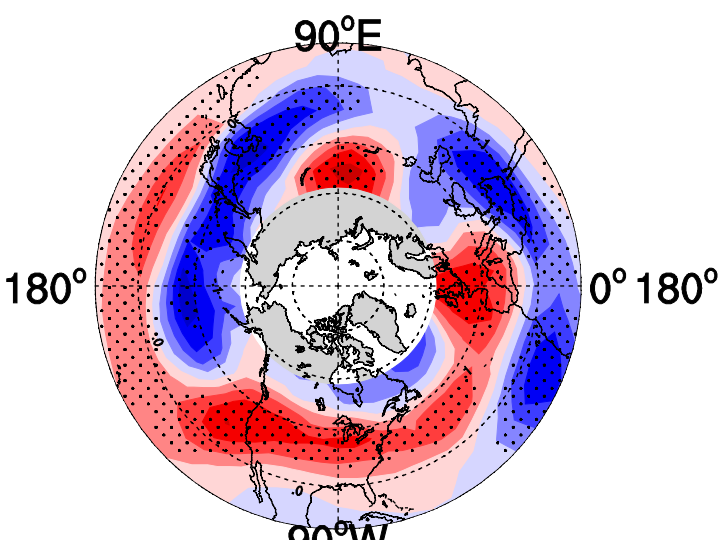

$90^{\circ} \widehat{\mathrm{W}}$

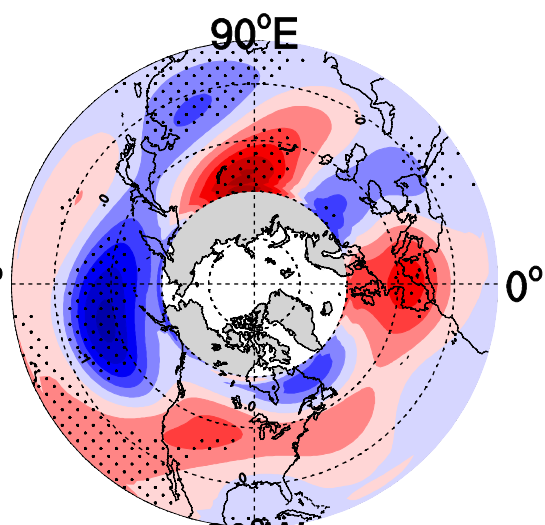

$90^{\circ} \widehat{\mathrm{W}}$

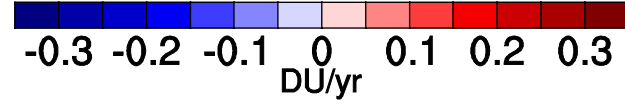

most of the northern middle latitudes shows positive trends except for the North Pacific and southern Atlantic Ocean where TCO still shows a decreasing trend. Trend analysis of zonal TCO anomalies shows that the positive trend in zonal TCO anomalies over northwestern North America is smaller but the positive trend over the eastern coast is larger than those during the 'ozone depletion' period (Fig. 3c, d). In addition, the center of maximum TCO decline shifts eastward and reaches over the North Pacific during the 'ozone recovery' period. The center of positive trend in zonal TCO anomalies over the Eurasian continent also shifts from the northeastern region of the Caspian Sea to the northeastern Asia. Overall, the wave- 3 structure of trends in zonal TCO anomalies shows an eastward shift during the 'ozone recovery' period relative to the period before. A similar eastward shift of zonal TCO anomalies in the Southern Hemisphere during the period 1979-2005 was also reported by Grytsai et al. (2007) and they attributed this phenomenon to the decadal changes in planetary waves. The LOTM reproduces the features of trends in zonal TCO anomalies over different regions as exhibited in ERA-Interim data during the two periods (Fig. 3e, f), suggesting that the ZAO changes are essentially related to the geopotential height variations during these periods. Note that the TCO trends in ERA-Interim data are larger than those in the LOTM simulations possibly because in the LOTM simulations the chemical ozone loss is not included. To reveal the influence of natural variabilities on ZAO trends and obtain more robust statistical signals, in the following we analyze the trends of TCO and geopotential height for the longer period 1979-2015.

The above result indicates that the geopotential height changes play a key role in the ZAO trends in the northern middle latitudes. Therefore, it is necessary to examine the trend of the geopotential height and the large-scale dynamical processes responsible for such a trend. Figure 4a shows the differences of geopotential height and horizontal winds 
Fig. 3 a, b Linear trends of DJF mean TCO derived from ERAInterim dataset for the period 1979-1997 and 1997-2015, respectively. $\mathbf{c}, \mathbf{d}$ are the same as $\mathbf{a}, \mathbf{b}$, but for zonal TCO anomalies. e, $\mathbf{f}$ Linear trends of DJF mean zonal anomalies of ozone column between 70 and $300 \mathrm{hPa}$ simulated by the LOTM for the period 1979-1997 and 1997-2015, respecively (a) TCO (1979-1997)

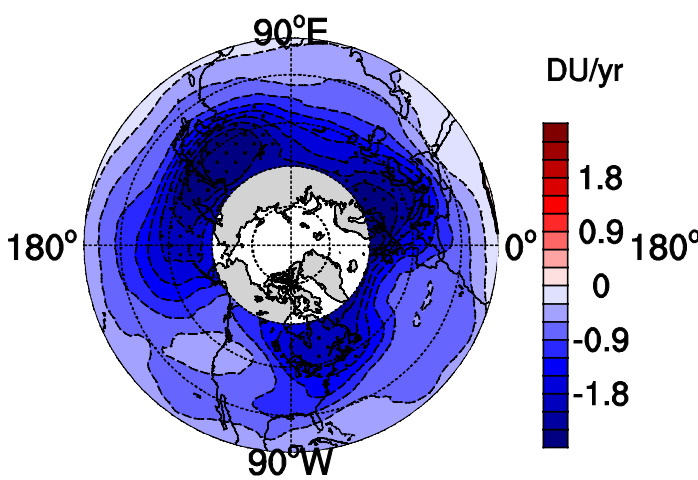

(c) TCOanom (1979-1997)

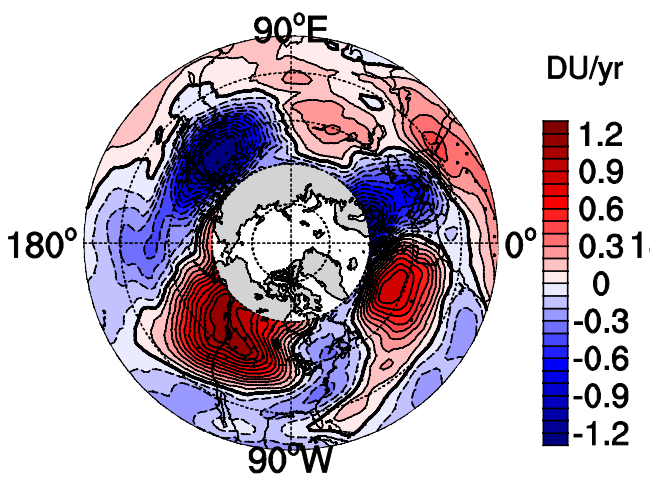

(e) LOTM TOZ (1979-1997)

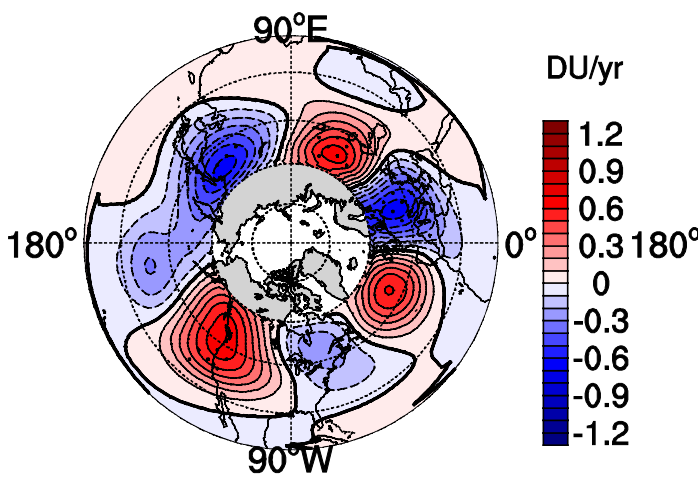

(b) TCO (1997-2015)

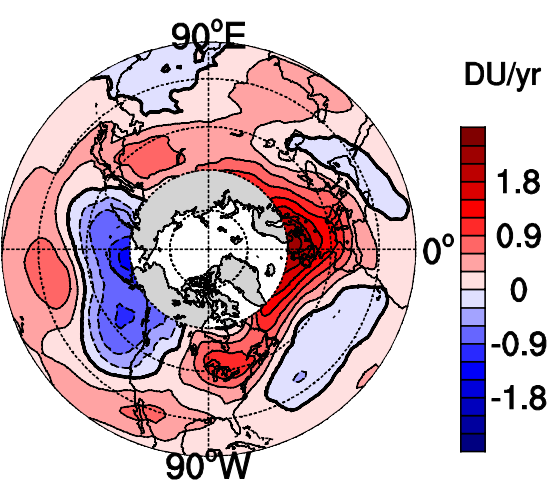

(d) TCOanom (1997-2015)

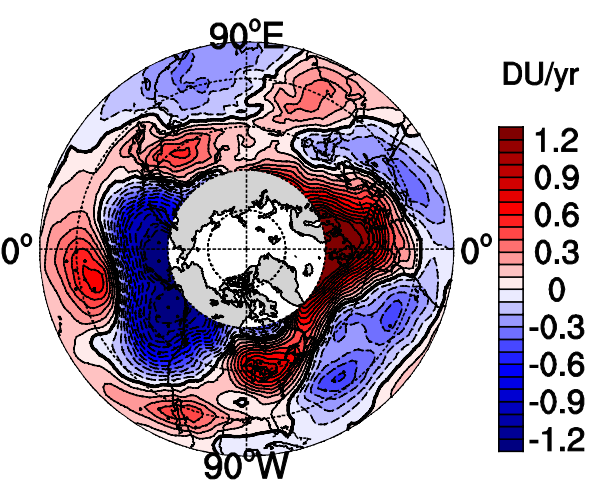

(f) LOTM TOZ (1997-2015)

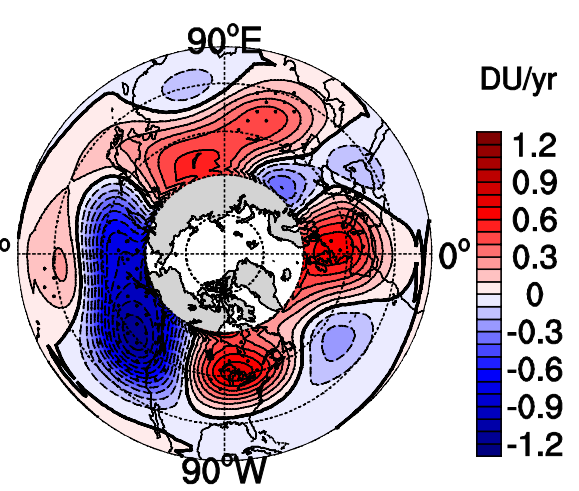

in the UTLS between the 2000s and 1980s. Note that there are positive height anomalies and anti-cyclonic flow anomalies over the North Pacific, the northeastern Asia and the North Atlantic regions; whereas, cyclonic flow anomalies and the negative height anomalies can be noted over the western coast of North America, South Atlantic and Central Siberia during the 2000s compared to the 1980s. Similar results have been also reported in previous studies which showed that the positive (negative) height anomalies in the UTLS lifted up (shifted down) ozone profiles and the associated anti-cyclonic (cyclonic) flows lead to the divergence (convergence) of the ozone concentrations in the UTLS, and thereby the TCO decreases (increases) (e.g. Wirth 1993;
Zhang et al. 2015). It should be pointed out that the above mentioned large-scale dynamical processes affecting TCO are also presented in the LOTM.

Figure 4b shows longitude-height cross-sections (along $45^{\circ} \mathrm{N}$ ) of geopotential height differences between the $2000 \mathrm{~s}$ and 1980s. The climatological mean of geopotential height is also overplotted for reference. The tropospheric height changes at middle latitudes are nearly barotropic above $500 \mathrm{hPa}$ and extend into the lower stratosphere. The geopotential height shows positive changes over the North Pacific, while there are negative height anomalies over northwestern North America and the Atlantic Ocean, suggesting that both the Aleutian Low and the Azores High 
(a)

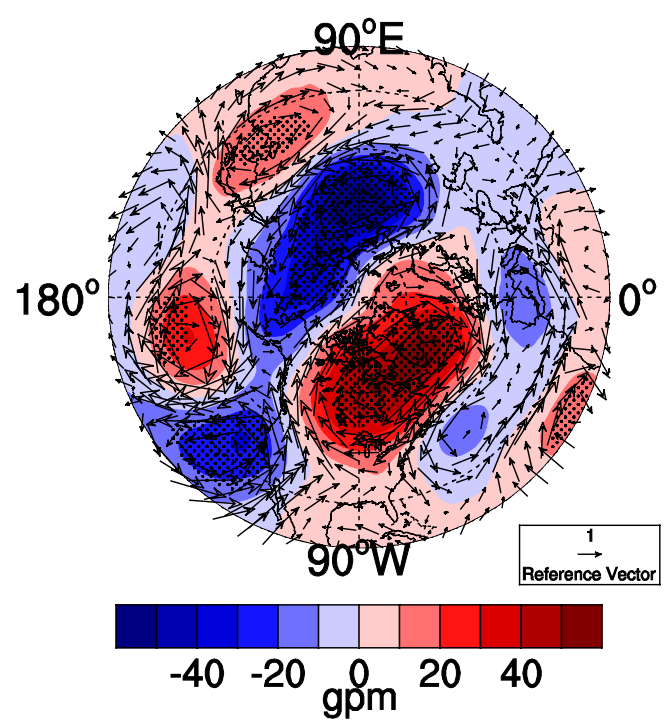

(c)

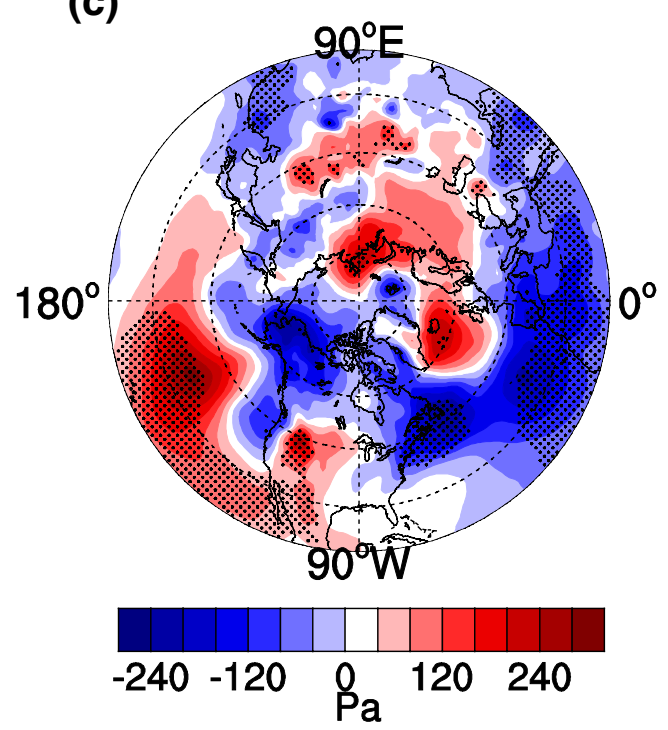

(b)

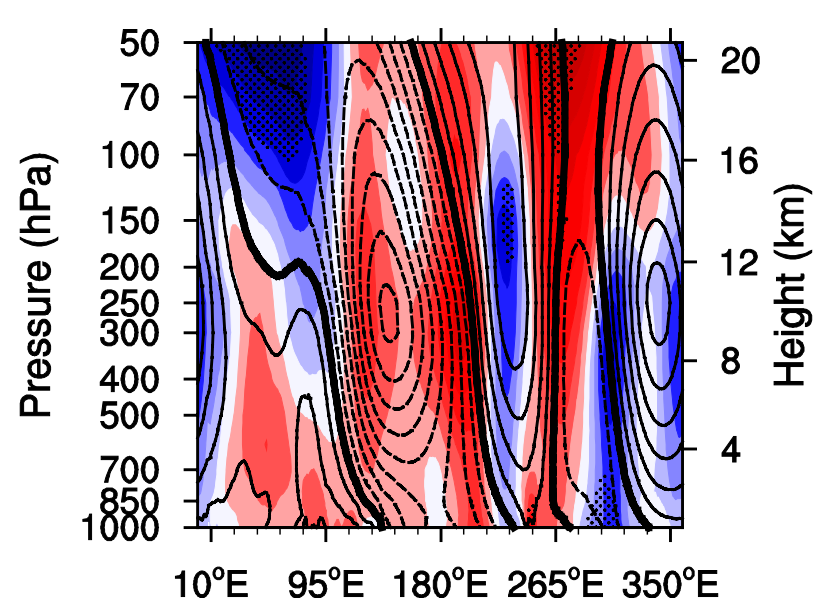

(d)
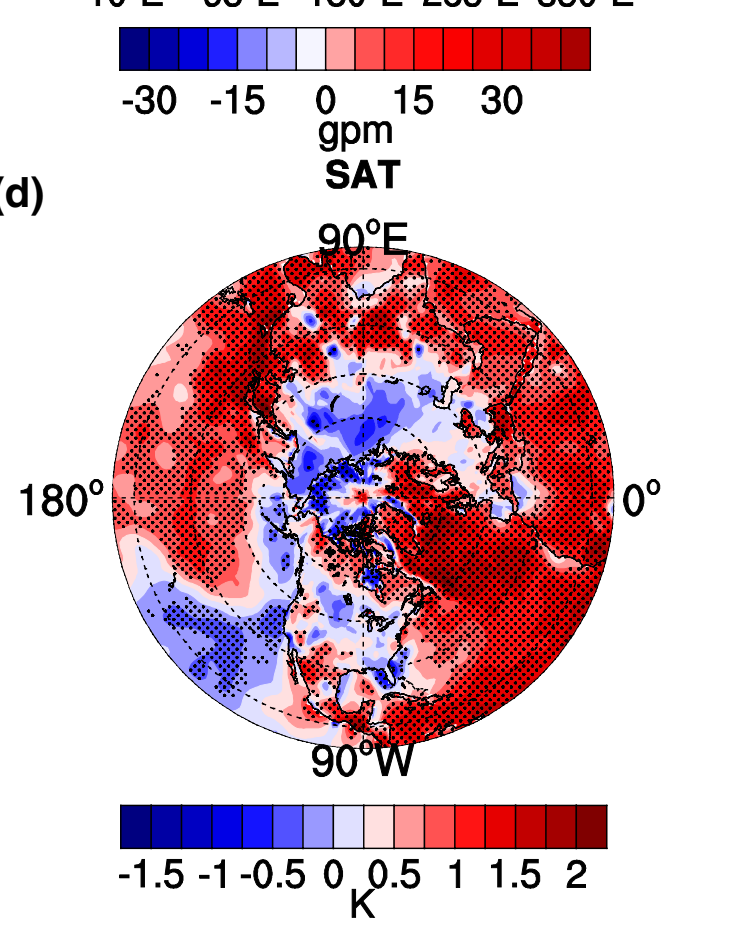

$40 \mathrm{~m}$, solid and dashed lines represent positive and negative lines, respectively). The sea surface temperature (SST) in $\mathbf{d}$ is derived from the NOAA Extended Reconstructed SST dataset and the land surface temperature uses CRU TS v3.22 data. The differences over the dotted regions are statistically significant at the $90 \%$ confidence level according to the Student's $t$ test

Icelandic Low and the Azores High are related to the negative trend of North Atlantic Oscillation (NAO)/AO for the period 1979-2015 (Fig. 6a). Also note that there are positive SLP changes over Siberia (Fig. 4c), implying that the Siberian High is enhanced, although the geopotential height anomalies around $90^{\circ} \mathrm{E}$ are negative throughout the middle and upper troposphere (Fig. 4b). Overall, the changes in the geopotential height and SLP during the 2000s relative to the 
1980s are of opposite sign to the trends of TCO anomalies (Fig. 1), particularly over the North Pacific and the Atlantic Ocean, further supporting the notion that the ZAO trends may be related to changes of tropospheric height and even surface pressure. Figure $4 d$ shows the decadal changes in the surface temperature. Note that the SST over the western and central North Pacific Ocean is increasing, while there are evident negative SST changes over the eastern tropical and extratropical Pacific, resembling a negative PDO-like SST pattern, favorable for the weakening of the Aleutian Low (Mantua et al. 1997). It should be pointed out that the SST changes over the Pacific Ocean during autumn are similar with those during winter (not shown), suggesting that the SST changes may precede the pressure and geopotential height changes. The increased SST over the Atlantic Ocean corresponds the weakening of the Azores High. In addition, the land surface temperature derived from CRU data (Harris et al. 2014) shows that Central Siberia has cooled for the period 1979-2015 (Cohen et al. 2012), corresponding to the deepening of the Siberian High. It is apparent that, the surface temperature trends are in accordance with the weakening of the Aleutian Low, Icelandic Low and Azores High, and their associated height changes.

The above analysis indicates that the geopotential height changes in the UTLS may be responsible for the ZAO trends. A question arises as to what processes control the geopotential height changes in the past decades. Figure 5 shows the spatial patterns of Empirical Orthogonal Function (EOF) analysis of the geopotential height at $500 \mathrm{hPa}, 300 \mathrm{hPa}$ and $100 \mathrm{hPa}$. The first three leading EOFs of geopotential height explain about $43 \%, 18 \%$ and $14 \%$ of the total variance at these three levels, respectively. The spatial pattern of the EOF1 is nearly identical to the AO pattern, as noted by Thompson and Wallace (1998), with a zonally symmetric seesaw pattern in geopotential height between the middle latitudes and high latitudes. The spatial pattern of EOF2 resembles the COWL pattern in surface temperature, which was first found by Wallace et al. (1995), and is an indicator of the thermal contrast between continents and oceans. The COWL pattern has a PNA-like structure over the eastern
Fig. 5 Spatial patterns (EOFs) of DJF mean of geopotential height at $\mathbf{a}-\mathbf{c} 500 \mathrm{hPa}, \mathbf{d}-\mathbf{f}$ $300 \mathrm{hPa}$ and $\mathbf{g}-\mathbf{i} 100 \mathrm{hPa}$ for the period 1979-2015. The number at the top right corner of each plot represents the percentage of explained variance
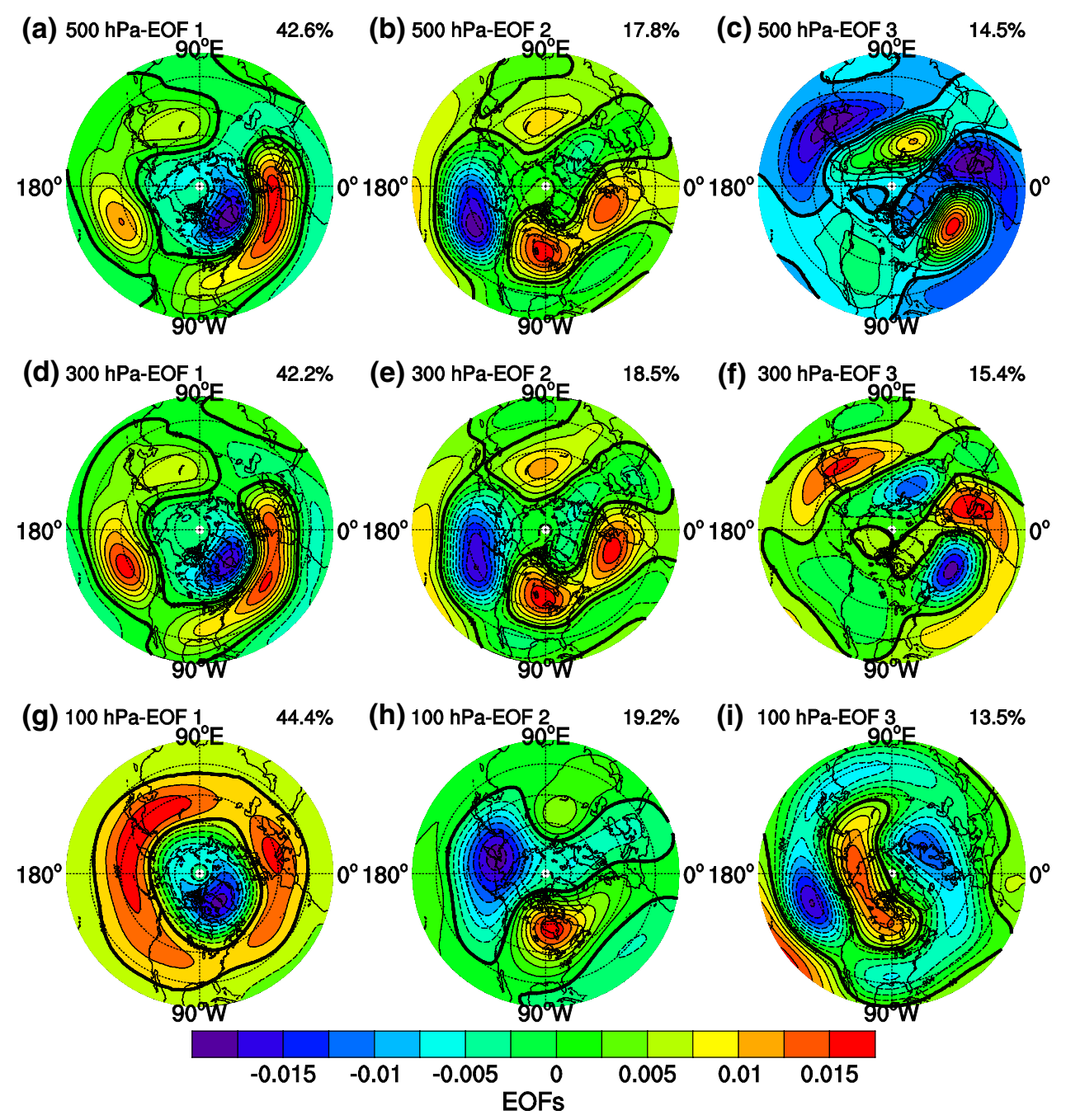
Pacific and the Continent of North America (Wu and Straus 2004a). Compared with the AO pattern, the COWL pattern also has the elements of the NAO pattern, but its center over the North Pacific has the same sign as the Arctic center and has the opposite sign to the North Atlantic center. The EOF2 also explains part of the variance of the geopotential height over Central Siberia where zonal TCO anomalies exhibit a positive trend. At $100 \mathrm{hPa}$, the COWL pattern is relatively weak, in particular for the center over Central Siberia, while the center over the North Pacific shifts westward. The spatial structure of EOF3 in the troposphere has no resemblance to any known teleconnection patterns and it is characterized by a north-south seesaw pattern between the middle latitudes and the subpolar regions accompanied by a north-south dipole over the Atlantic Ocean. However, it is interesting that the structure of EOF3 at $100 \mathrm{hPa}$ over the North Pacific regions resembles the North Pacific pattern found by Trenberth and Hurrell (1994). Overall, the leading three EOFs explain most of the total variance (about 75\%) of geopotential height over the North Pacific region where a maximum negative trend of TCO and zonal TCO anomalies for the period 1979-2015 can be noted (Fig. 1).

Figure 6 shows principal component (PC) time series of the first three leading EOFs of the geopotential height at $500 \mathrm{hPa}, 300 \mathrm{hPa}$ and $100 \mathrm{hPa}$. The PC1 is found to be highly correlated with the $\mathrm{AO}$ index from the troposphere to the stratosphere. Although the correlation coefficient decreases with height, the correlation coefficient between the PC1 of geopotential height at $100 \mathrm{hPa}$ and the $\mathrm{AO}$ index can be up to -0.71 (statistically significant at $99 \%$ confidence level), suggesting a close coupling between the troposphere and the stratosphere. The PC2 of the geopotential height in the troposphere and the stratosphere are highly correlated with the COWL index. The significant correlation between PC2 and the COWL index suggests that the land-sea thermal contrast could exert a significant influence on the geopotential height in the troposphere and even in the lowermost stratosphere. Particularly noticeable is that the COWL index shows a negative trend during the period 1979-2015 (Fig. 6b), corresponding to the weakening of the Aleutian Low, Icelandic Low and Azores High (Fig. 4b, (a)
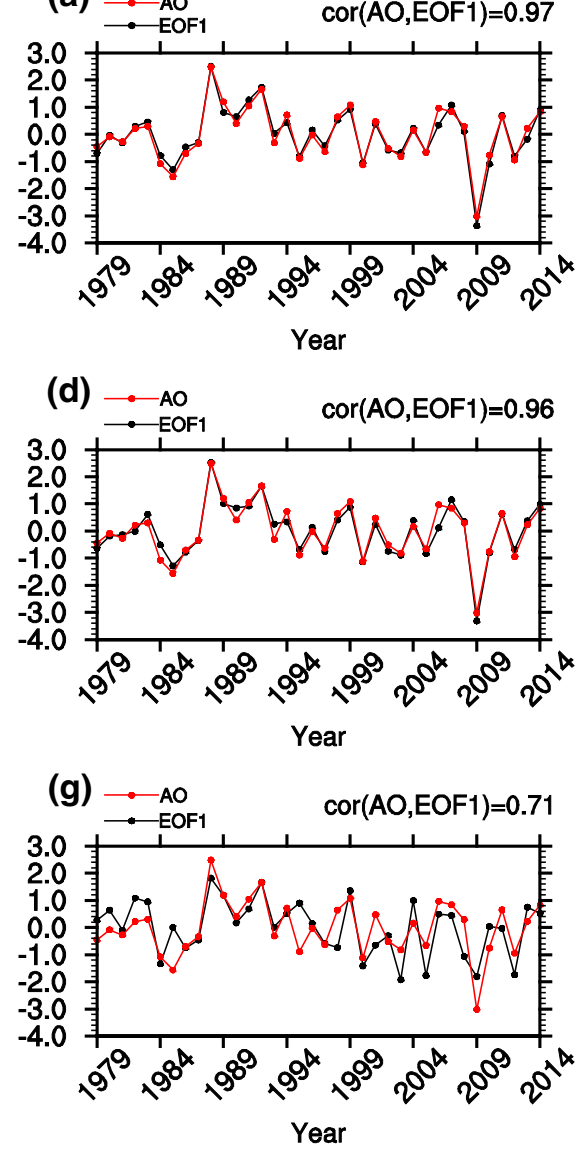

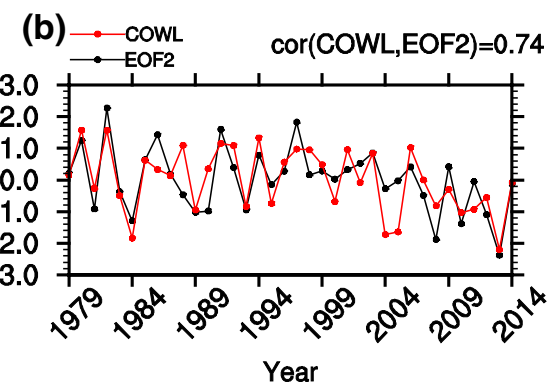

(e)

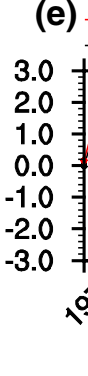

(h)

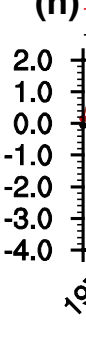

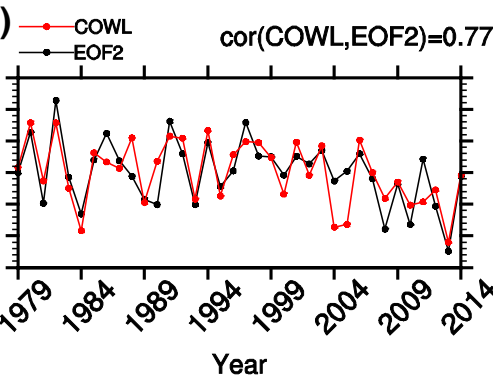

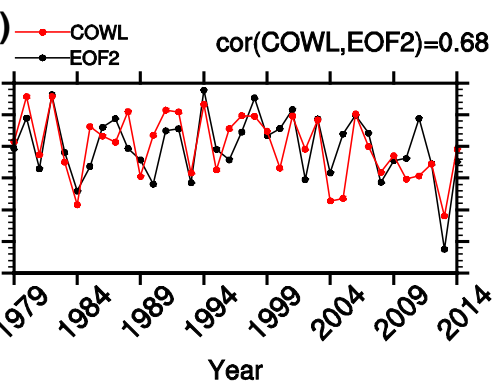

(c)
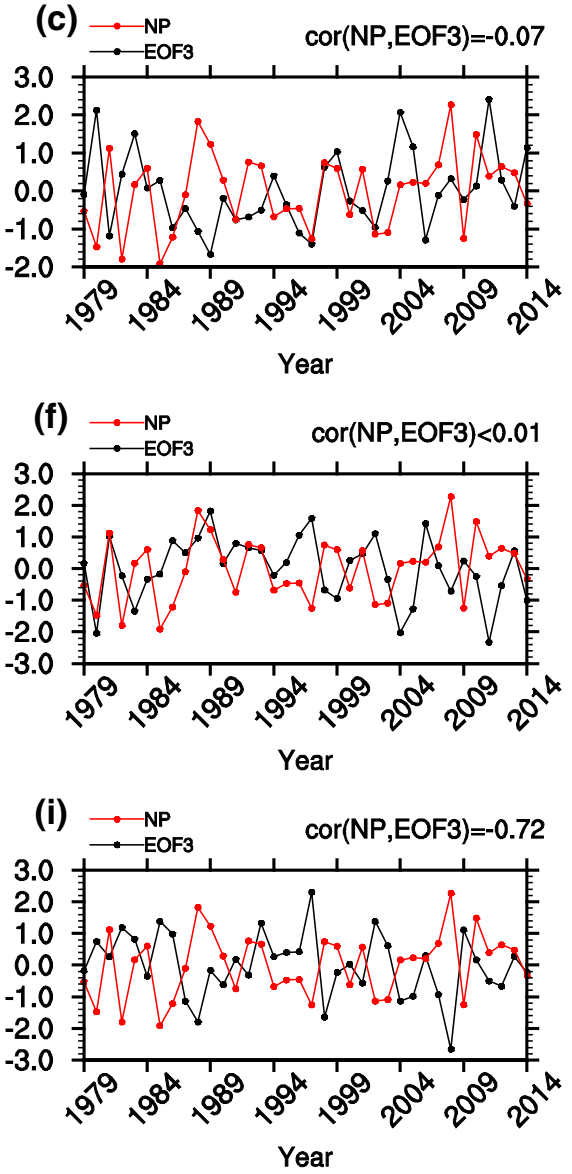

Fig. 6 Time series of standardized a, $\mathbf{d}$, $\mathbf{g}$ principal component (PC)1, b, e, h PC2, and $\mathbf{c}, \mathbf{f}, \mathbf{i}$ PC3 of DJF mean geopotential height at $\mathbf{a}-\mathbf{c} 500 \mathrm{hPa}, \mathbf{d}-\mathbf{f} 300 \mathrm{hPa}$ and $\mathbf{g}-\mathbf{i} 100 \mathrm{hPa}$. Time series of AO,
COWL and NP pattern index are also overplotted. The number on the upper right corner of each plot represents the correlation coefficient between EOFs and teleconnection pattern index 
c) in this period. It is also interesting that the PC3 of the $100 \mathrm{hPa}$ geopotential height has an anti-correlation with the NP index, with a correlation coefficient of -0.72 ; however, there is no significant correlation between the tropospheric PC3 and the NP index. This is possibly because the EOF2 explains the majority of tropospheric height variations over the North Pacific while the EOF3 only explains a small part. Overall, the AO and COWL could account for most of the geopotential height variations at northern middle latitudes during winter, consistent with the results of $\mathrm{Wu}$ and Stratus (2004a, b). If the AO, COWL and NP patterns are all included to regress the geopotential height, the lowermost stratospheric height variations can be better reconstructed than only using the AO and COWL.

Figure 7 shows the trend projections of the zonal TCO anomalies onto the three patterns. A multiple linear regression (MLR) model is applied to the data for DJF mean of zonal TCO anomalies and can be represented as follows:

$Z A O(t)=\alpha^{0}+\alpha^{A O} \cdot A O(t)+\alpha^{C O W L} \cdot C O W L(t)+\alpha^{N P} \cdot N P(t)+\varepsilon(t)$, where $t$ is the time in 1-year increments, $\alpha^{0}$ is the long-term mean for DJF mean data, $\alpha^{x}$ is the contribution coefficient of DJF mean proxy $x$ and $\varepsilon(t)$ represents the residual time series. The selected proxies include Arctic Oscillation (AO),

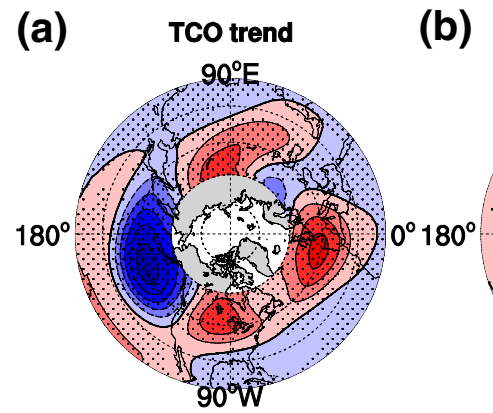

(c)

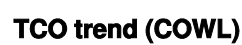

(d)
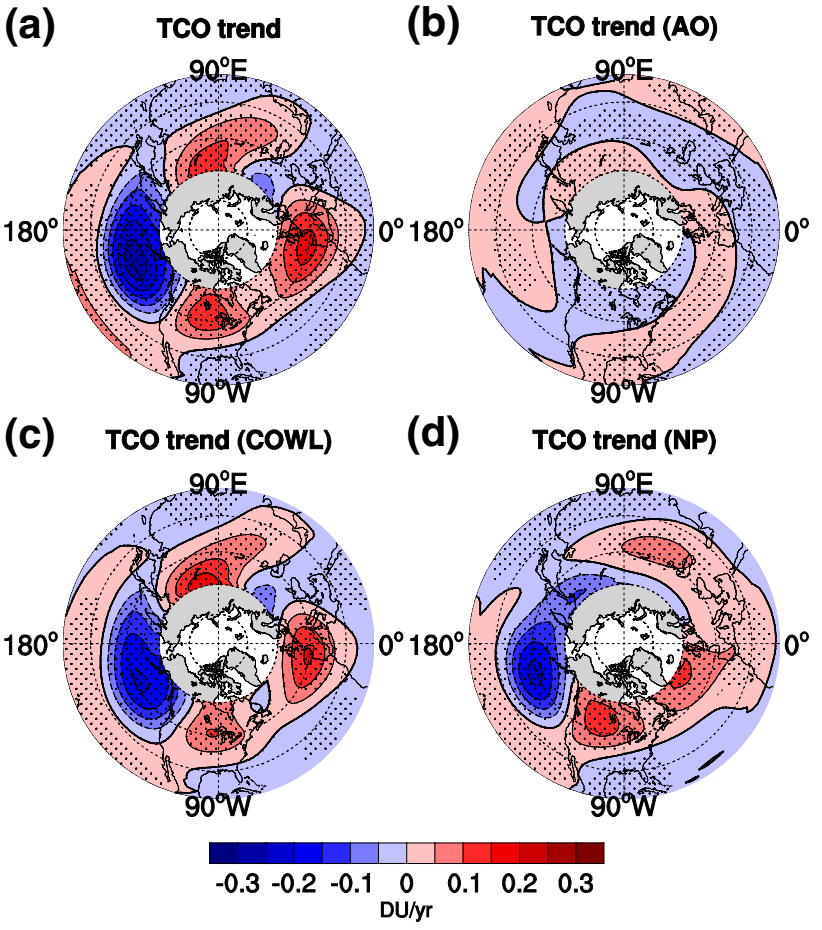

Fig. 7 Linear trends for the period 1979-2015 in DJF mean TCO: a the total trend attributed to the AO, COWL and NP, the components of the trend attributed to the $\mathbf{b}$ AO, $\mathbf{c}$ COWL and $\mathbf{d}$ NP patterns. The dotted regions represent the regions where zonal TCO anomalies are significantly regressed on the AO, COWL and NP index at the $90 \%$ confidence level according to the Student's $t$ test
Cold-Ocean Warm Land (COWL) and North Pacific (NP) index. The MLR trends of TCO anomalies using the three pattern indices are also shown (Fig. 7a) and the regressed trend is very close to the sum of the three trend projections using separate teleconnection patterns. Overall, the regressed trends of zonal ozone anomalies in the UTLS agree well with those derived from the observations (Fig. 1b, d, f) and the LOTM simulations (Fig. 2d), with negative trends over the North Pacific and positive trends over the Continent of North America, the southern Atlantic Ocean and Central Siberia, although in the regression model the negative center of TCO trend over the northern Atlantic Ocean disappears. The magnitudes of the regressed TCO trends over the North Pacific, Central Siberia and Europe are nearly identical to those values shown in Fig. 1b, d, f. Also note that the COWL pattern and NP pattern together dominate the ZAO trend pattern, while the AO pattern explains a small part. This is understandable since the AO pattern represents the zonally symmetric structure of atmospheric circulation. The NP-related ZAO centers over North America and Central Siberia may be attributed to the downstream effects of NP teleconnection (Linkin and Nigam 2008). It can be seen from Fig. 7 that the positive trend in zonal TCO anomalies over Central Siberia is mainly attributed to the COWL change whereas the NP change explains a smaller part. The negative trend in zonal TCO anomalies over the North Pacific is also caused by the changes in COWL and NP patterns. Also note that the changes in COWL and NP patterns have almost the same contributions to the positive trend over North America. In fact, the AO, COWL and NP patterns reflect most of the tropospheric climate variability (Wu and Straus 2004a); accordingly, the main feature of the ZAO trends are well captured by the TCO changes associated with the three patterns, particularly for the COWL and NP patterns, suggesting that tropospheric climate change may exert a significant influence on the ZAO trend in the northern middle latitudes.

\section{The impact of the surface temperature on ZAO trend}

It has been found that the ZAO trend is related to tropospheric planetary waves and teleconnection patterns. Some studies reported that long-term changes in the atmospheric teleconnection pattern and planetary wave can be significantly affected by external forcing such as SST changes (e.g. Janicot et al. 2001; Czaja and Frankignoul 2002; Allen and Zender 2011; Hu et al. 2017; Zhou et al. 2017; $\mathrm{Li}$ et al. 2018). Therefore, it is worth examining the impact of SST changes on the zonally asymmetric TCO trend. Here, we perform WACCM3 experiments with and without prescribed SST trends to clarify the importance of the 
Fig. 8 Linear trends of zonal anomalies of $\mathbf{a}-\mathbf{c}$ TCO and $\mathbf{d}-\mathbf{f}$ geopotential height averaged between 70 and $300 \mathrm{hPa}$ during winter in run $\mathbf{a}, \mathbf{d} \mathbf{R 0}$ (see details in Sect. 2), b, e R1, and c, $\mathbf{f} \mathbf{R} 2$ derived from WACCM3. The linear trends over the dotted regions are statistically significant at the $90 \%$ confidence level according to the Student's $t$ test

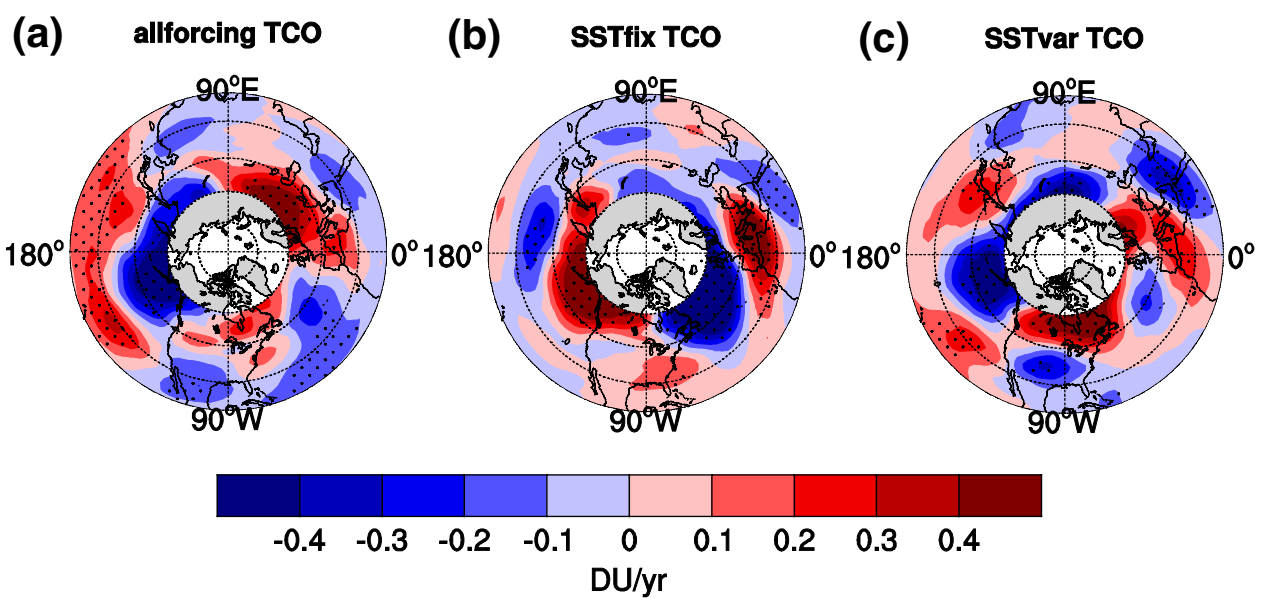

(d) allforcing Z 70-300hPa

(e) SsTflx Z 70-300hPa

(f) SSTvar Z 70-300hPa
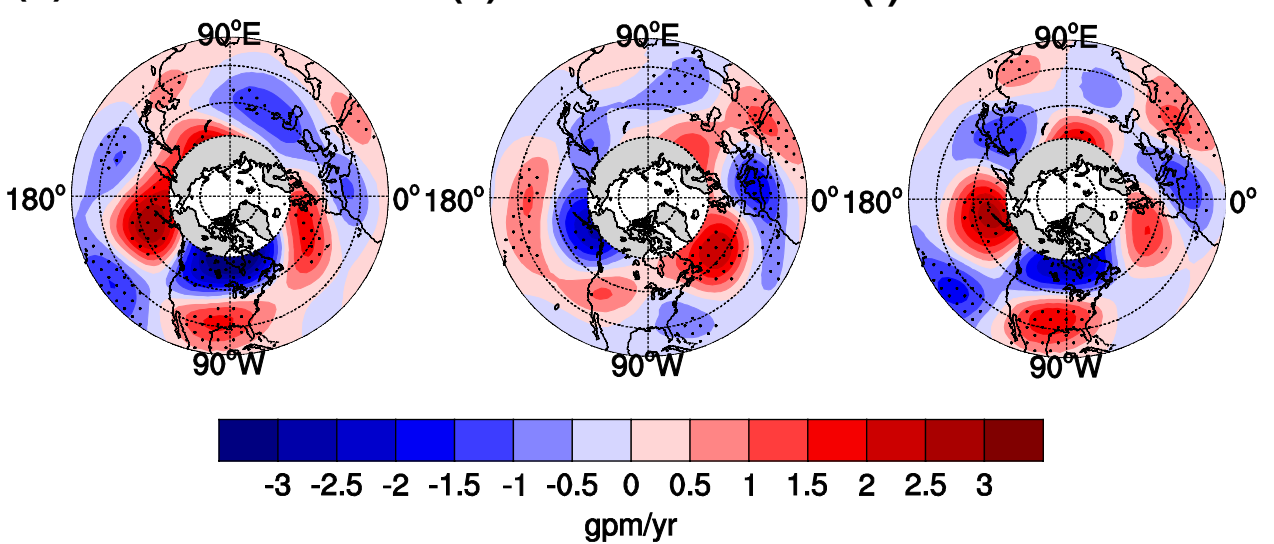

impact of SST changes on the ZAO trends. The detailed configurations of the experiments (R0, R1 and R2) are described in Sect. 2. Figure 8a shows the linear trends in the simulated zonal TCO anomalies in R0 (with all forcings). The anti-correlation between zonal TCO anomalies (Fig. 8a-c) and the geopotential height (Fig. 8d-f) averaged between 70 and $300 \mathrm{hPa}$, which is evident in the reanalysis data and the SLIMCAT simulation, are well reproduced by the WACCM3. The PNA-like pattern in trends of zonal TCO anomalies in R0 is also similar to that in the NIWA, ERA-Interim data and the SLIMCAT simulation (Fig. 1d, f, h), although the positive center of the PNA pattern shows a more northeastward shift in R0. A belt of negative trends in zonal TCO anomalies over northeastern Asia and the North Pacific are also reproduced by run R0. The west-east dipole structure in trends of the zonal TCO anomalies over the Euro-Atlantic region simulated by run R0 is similar to that in the reanalysis data (Fig. 1d, f). In addition, the positive trend of zonal TCO anomalies over Central Siberia is also captured by run R0. Overall, the WACCM3 model captures most features of ZAO trends seen in the reanalysis data and the SLIMCAT simulation. An exception is that the NAO-like TCO anomalies in the reanalysis data cannot be seen in run R0.
Also note that the simulated positive TCO trend over Siberia by $\mathbf{R 0}$ is stronger and more westward than that in the NIWA and ERA-Interim data, possibly due to the COWL pattern being somewhat different from that simulated by the WACCM3, although the COWL index in R0 is significantly correlated to the COWL index in reanalysis data, with a correlation coefficient of 0.5 (Fig. 9a, b).

Figure 8b, e show the trends in zonal anomalies of TCO and geopotential height simulated by $\mathbf{R} \mathbf{1}$ with a monthly mean SST climatology. Although there is also a 'ZAO' trend in $\mathbf{R} 1$, the trend map is thoroughly different from that in R0, the reanalysis data and the SLIMCAT simulation. The trends in zonal anomalies of geopotential height in the UTLS (Fig. 8e) are also quite different from those in R0. Furthermore, the simulated PC2 in $\mathbf{R} 1$ is not significantly correlated with the COWL index in reanalysis data (Fig. 9c, d). In contrast, in run $\mathbf{R 2}$, which has fixed ODSs and prescribed SST changes, the linear trends in zonal anomalies of TCO and geopotential heights in the UTLS are nearly the same as those in run R0. There is also a statistically significant correlation coefficient $(0.34)$ at $90 \%$ confidence level between PC2 in $\mathbf{R 2}$ and COWL derived from the reanalysis data (Fig. 9e, f). In summary, the WACCM3 simulations further support that SST changes have important effects on 
Fig. 9 a, c, e EOF2 spatial patterns of DJF mean of geopotential height at $500 \mathrm{hPa}$ and $\mathbf{b}, \mathbf{d}$, f time series of standardized $\mathrm{PC} 2$ of DJF mean geopotential height at $500 \mathrm{hPa}$ (black line) derived from run $\mathbf{a}, \mathbf{b} \mathbf{R 0}, \mathbf{c}, \mathbf{d}$ $\mathbf{R 1}$, and e, $\mathbf{f} \mathbf{R 2}$. Time series of COWL pattern index derived from the ERA-Interim reanalysis data (red line) are also overplotted in the right panel. The number at the top right corner of $\mathbf{a}, \mathbf{c}, \mathbf{e}$ represents the percentage of explained variance by EOF2. The number on the upper right corner of each plot in $\mathbf{b}, \mathbf{d}, \mathbf{f}$ represents the correlation coefficient between $\mathrm{PC} 2$ in each experiment and COWL pattern index

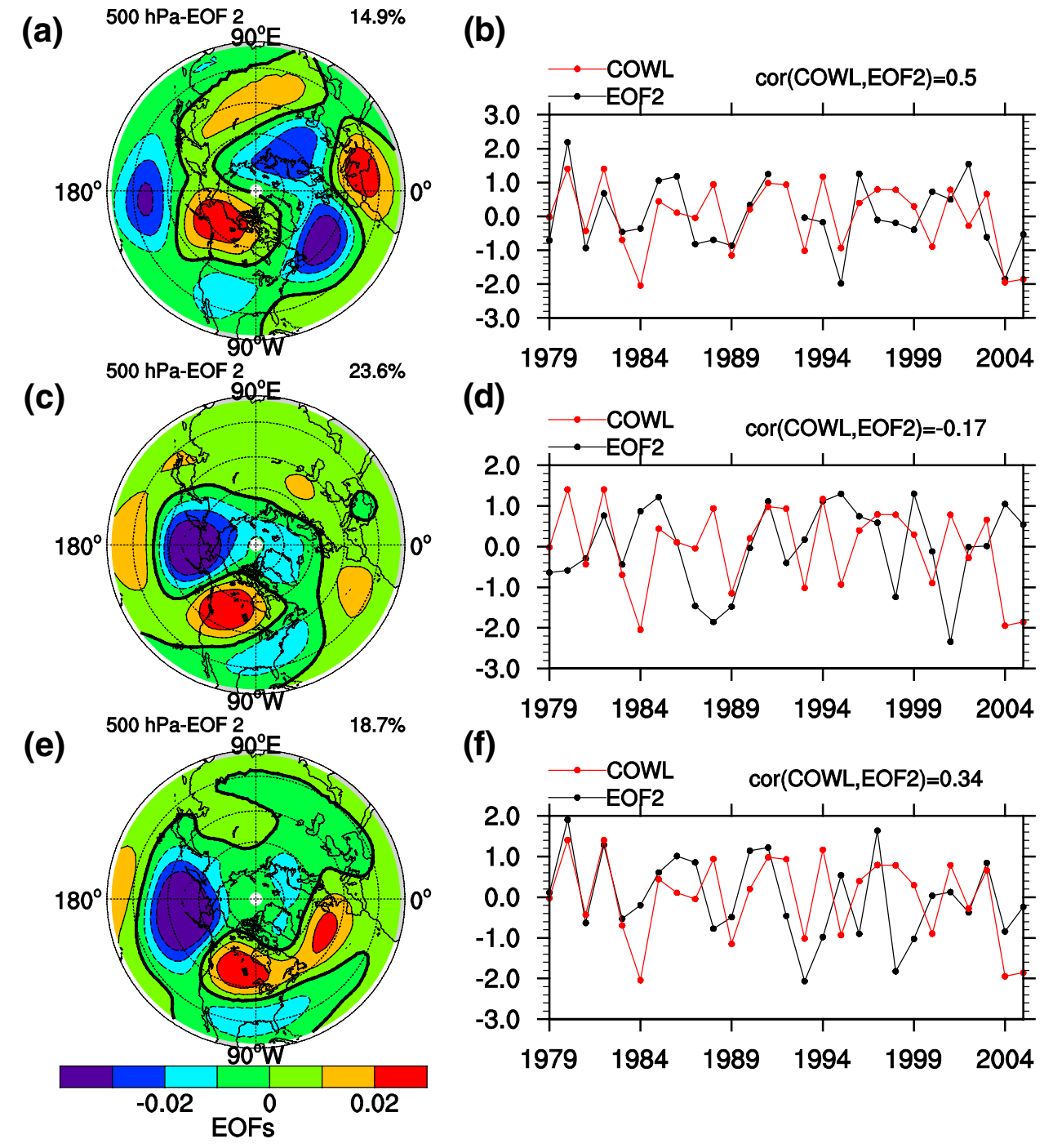

the observed trends of ZAO and geopotential heights, particularly over the North Pacific.

Figure 10a shows the correlation coefficients between DJF mean zonal TCO anomalies over the North Pacific and global SSTs during winter. We can see that there are significant negative correlations over the central North Pacific and positive correlations along the western coast of North America and over the eastern equatorial Pacific. The warming over the central North Pacific (Fig. 4d) gives rise to the positive height trends over the North Pacific, corresponding to the weakening of the Aleutian Low, and hence, TCO decreases. In addition, a negative-phase PDO-like SST trend pattern (Fig. 4d) is responsible for the weakening of the Aleutian Low (Wendler et al. 2014) and leads to positive correlations between TCO anomalies and SSTs over the eastern tropical and extratropical Pacific Ocean. There are also high correlations between North Pacific TCO and SST variations over the Indian
Ocean and South Pacific Ocean, which may be related to the non-local effects of the Inter-decadal Pacific Oscillation (IPO) (Parker et al. 2007; Dong and Dai 2015). By contrast, the correlations (not shown) between zonal TCO anomalies averaged over northwestern North America and SSTs are of opposite sign to the correlations of zonal TCO anomalies over the North Pacific, suggesting that the SST changes have a significant contribution to the positive TCO trends over northwestern North America (Fig. 1).

Figure $10 \mathrm{~b}$ shows the correlation coefficients between DJF mean of zonal TCO anomalies averaged over the Azores and adjacent ocean and global SST variations during winter. There are significant positive correlations over the Iceland and the tropical Atlantic Ocean and negative correlations over the Azores during winter, which shows a NAO-like correlation pattern. The significant NAO-like correlation between TCO and Atlantic SST seems to contradict the finding that $\mathrm{AO} / \mathrm{NAO}$ only explained a small component of TCO 
(a)

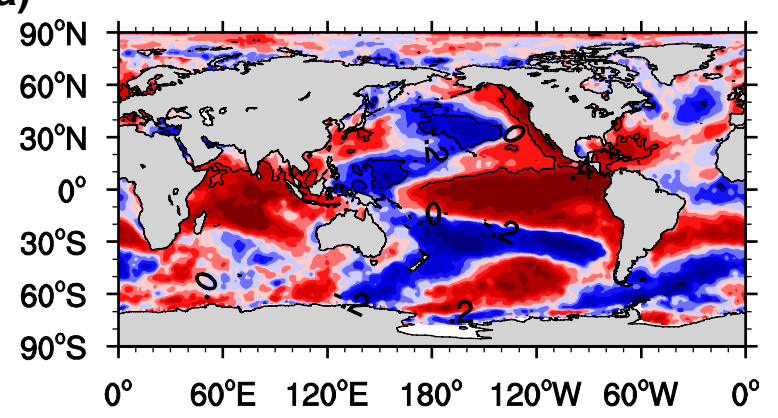

(b)

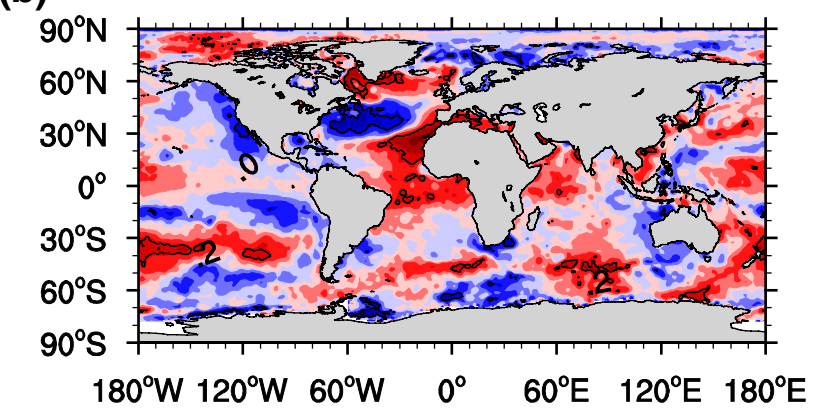

(c)

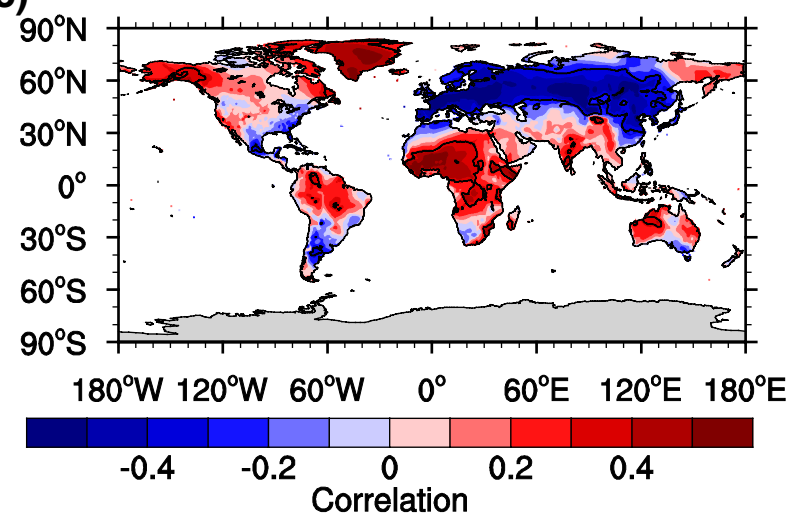

Fig. 10 a Correlation coefficients between DJF mean of zonal TCO anomalies averaged over the North Pacific region $\left(45^{\circ} \mathrm{N}, 180^{\circ}-\right.$ $210^{\circ} \mathrm{E}$ ) and global SST. b Correlation coefficients between DJF mean of zonal TCO anomalies over the Azores and adjacent ocean $\left(45^{\circ} \mathrm{N}\right.$, $\left.30^{\circ}-60^{\circ} \mathrm{W}\right)$ and global SST. c Correlation coefficients between DJF mean of zonal TCO anomalies over Central Siberia $\left(55^{\circ} \mathrm{N}, 85^{\circ}\right.$ $120^{\circ} \mathrm{E}$ ) and global land surface temperature. The black lines enclose the region in which correlation coefficients are statistically significant at the $90 \%$ confidence level according to the Student's $t$ test

trend over the Atlantic Ocean (Fig. 7b). This is possibly related to the polar vortex shifting away from North America (Zhang et al. 2016), leading to negative PV anomalies associated with anti-cyclonic flows and positive geopotential height anomalies in the UTLS over the northern part of the Atlantic Ocean (Fig. 4a). It is accompanied by negative height anomalies over the southern part of the Atlantic Ocean (Fig. 4a) due to stratospheric Northern Annular Mode variability (Limpasuvan and Hartmann 2000). The NAO-like
UTLS geopotential height anomalies could cause NAO-like TCO anomalies. The above analysis results suggest that the NAO-like correlation and trends in TCO (Fig. 1) is partially explained by the stratospheric polar vortex variability, rather than merely due to the tropospheric NAO teleconnection, which is consistent with the conclusion of Ambaum and Hoskins (2002).

The correlation coefficients between the DJF mean of zonal TCO anomalies over Central Siberia and land surface temperature changes in winter are shown in Fig. 10c. Note that there are negative correlations over the midhigh latitude Eurasian continent during winter. The cooling land surface temperature over Central Siberia (Fig. 4d) decreases the tropopause height and produces a negative COWL trend (Fig. 6b) which is responsible for the positive trend in zonal TCO anomalies over this region (Fig. 1). In addition, the positive correlation between TCO anomalies over Central Siberia and the surface temperature variations over Greenland (Fig. 10c) may also be related to the COWL teleconnection (Wu and Stratus 2004a; He et al. 2014).

Finally, it is worth discussing the impacts of chemical processes on the ZAO trend. To quantify chemical ozone changes, the SLIMCAT off-line model (see details in Sect. 2) is employed. Although the ozone decline due to chemical processes has ceased and is likely beginning to reverse (Chipperfield et al. 2017), here we just analyze the contribution of chemical processes to the ZAO trend over the period 1979-2015 and do not attempt to separate the 'ozone recovery' period from the 'ozone depletion' period. Figure 11a shows the linear trends of zonal anomalies of chemical TCO (see Sect. 2). Note that the trends of chemical ozone in the northern middle latitudes are also longitude-dependent, with negative trends of zonal TCO anomalies over Central Siberia, but positive trends over the Bering Sea and Alaska. Figure 11b shows the vertical distribution of chemical ozone trends over Central Siberia. It is found that there are negative chemical ozone trends corresponding to an enhanced chemical ozone loss throughout the stratosphere for the period 1979-2015, and the most evident ozone decline occurs at $30 \mathrm{hPa}$. In the UTLS $(\sim 300-70 \mathrm{hPa})$, the ZAO trend largely depends on changes in large-scale dynamical processes. Zhang et al. (2018) found that more Arctic poor-ozone air rich in active chlorine was transported to Siberia since 1980 leading to stronger chemical ozone loss as a consequence of the Artic polar vortex shift towards Eurasia (Zhang et al. 2016). Therefore, the strong chemical TCO decline over Siberia and simultaneous increase in ozone over Alaska (Fig. 11a) may be related to the Artic polar vortex shift towards Siberia. Meanwhile, the positive trend in the simulated zonal TCO anomalies by the LOTM (Fig. 2d) in the absence of chemical ozone loss is larger over Central 
Fig. 11 a Linear trends for the period 1979-2015 of DJF mean chemical TCO (see details in Sect. 2) derived from SLIMCAT simulations. The linear trends over the dotted regions are statistically significant at the 90\% confidence level according to the Student's $t$ test. b Vertical distribution of linear trends in chemical ozone averaged over $50^{\circ}-70^{\circ} \mathrm{N}, 60^{\circ}-90^{\circ} \mathrm{E}$. The error bars represent two- $\sigma$ uncertainties

\section{(a) TCO CHEM LOSS}

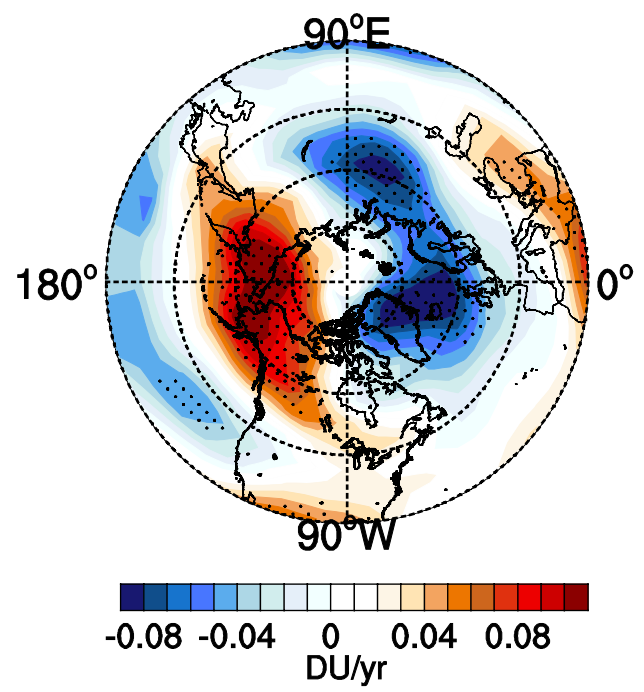

(b)

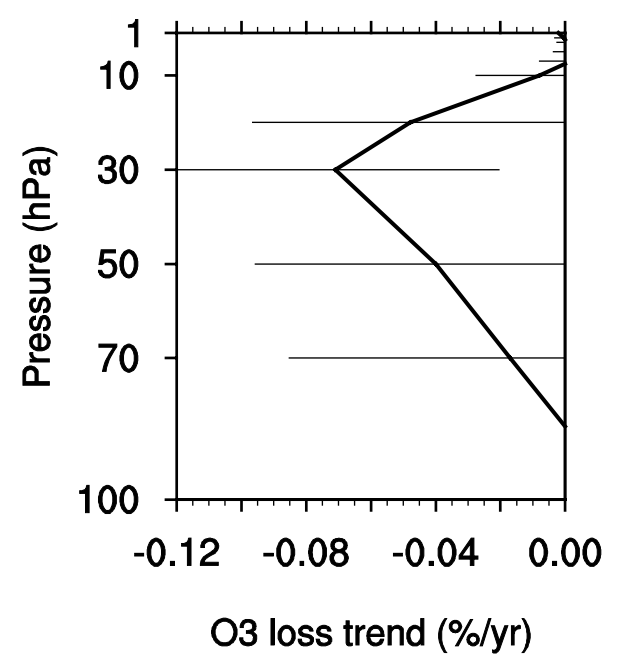

Siberia, while the positive trend over northwestern North America from the LOTM simulation is smaller than those in the ERA-Interim data (Fig. 1d), which is closely related to the impact of chemical processes on ZAO trends. Overall, the above analysis suggests that chemical processes also contribute to the ZAO trend; however, the contribution of chemical processes to trends in zonal TCO anomalies (Fig. 11) is smaller than that of dynamical processes (Fig. 2d).

\section{Summary and discussion}

In this paper, we analyzed the zonally asymmetric TCO trends at the northern middle latitudes for the period 1979-2015. The main factors responsible for these trends are diagnosed using various data sets, a linear ozone transport model (LOTM), a chemistry-climate model (WACCM3) and an offline chemical transport model (SLIMCAT). It is found that there are maximum decreasing TCO trends over the North Pacific and relatively weaker decreasing TCO trend over the northern Atlantic Ocean and the northern Caspian Sea in winter, while increasing TCO trends are noted over northwestern North America and Central Siberia, suggesting that the ozone trends in northern mid-latitude winter are longitude-dependent. The LOTM results indicate that the trends in zonal anomalies of the partial ozone column between 70 and $300 \mathrm{hPa}$ contribute most to the zonally asymmetric TCO trend at northern middle latitudes, and this result is also supported by ERA-Interim and MERRA reanalysis data. It is also found that the ZAO trends are closely related to the long-term changes in the geopotential height extending from the middle troposphere to the lower stratosphere. The positive (negative) height changes and associated anomalous anti-cyclonic (cyclonic) flows tend to change the vertical distribution of ozone via ozone transport in the UTLS, leading to TCO decreases (increases). Similar conclusions can be drawn during either the 'ozone depletion' period (1979-1997) or the 'ozone recovery' period (1997-2015), based on a piecewise trend analysis.

EOF analysis of the geopotential height in the troposphere and lower stratosphere reveals that the first leading mode resembles the AO pattern. The second mode looks like the COWL pattern that is related to the large-scale land-sea thermal contrast. It is interesting that the third mode of the lowermost stratospheric height (100 hPa) variations is significantly correlated to the NP pattern. Furthermore, the main features of the ZAO trends are related to changes in the COWL and NP patterns, while the AO pattern can only explain a minor component of the ZAO trends. Our results also suggest that the negative trend in COWL and positive trend in NP index are related to the weakening of the Aleutian Low during 1979-2015, extending from the surface to the lower stratosphere, which have a significant impact on the ZAO trends at northern middle latitudes.

Further analysis reveals that variations in zonal TCO anomalies over the North Pacific, the Atlantic Ocean and Central Siberia have good correlations with surface temperature changes over these regions. In addition, the WACCM3 model experiment with prescribed SST trends reproduces similar trends of zonal TCO anomalies as found in NIWA observations and reanalysis data; however, the model experiment without interannual SST variability did not. Therefore, both the observations and model results confirm that the changes in the surface temperature can significantly influence the ZAO trend and imply a longitude-dependent return dates of TCO at northern middle latitudes in the future. 
Relative to the large-scale dynamical effects, the chemical effects on the zonally asymmetric TCO trend are smaller. Enhanced chemical ozone loss partially offsets the dynamically-driven positive trends in zonal TCO departures over Central Siberia, while simultaneous ozone increases over Alaska strengthen the dynamically-driven positive trend of zonal TCO departure over northwestern North America. The enhanced ozone chemical loss over Central Siberia may be related to more Arctic air with high levels of active chlorine radicals transported towards the region (Zhang et al. 2018), as a result of the shift of the Arctic stratospheric polar vortex towards Central Siberia since 1980.

In this study, we have shown that the changes in tropospheric teleconnection patterns (especially the COWL pattern) associated with surface temperature changes and atmospheric internal variability could exert a significant influence on the planetary wave structure in the UTLS geopotential heights. Consequently, the longitude-dependent TCO trends and the regional stratospheric ozone recovery rate could be affected by the surface temperature changes. This result highlights the importance of improving General Circulation Model's and Chemistry Climate Model's abilities to simulate surface temperature and associated tropospheric teleconnection patterns for the purpose of more reasonably predicting the interannual variability and long-term trend of TCO in the northern middle latitudes.

Previous studies used an observed stratospheric zonal ozone anomaly during the ozone depletion period to force a climate model and found that the ZAO anomaly could induce a weakening of the Iceland Low and a shift of tropospheric circulation towards the negative phase of NAO (Gabriel et al. 2013; Peters et al. 2015). Consequently, the negative TCO trend over the northern part of the Atlantic Ocean will be more negative and the ZAO structure may be strengthened. By contrast, the asymmetric ozone anomaly will cause an intensification of the Aleutian Low, leading to a negative feedback effect on the ZAO structure, i.e., smoothing the mid-latitude ZAO trend, according to our study. Overall, the feedback effects of ZAO on tropospheric circulation are complicated and deserve more investigation in the future.

Acknowledgements This work is supported by the National Science Foundation of China (41705022, 41575038, 41575039 and 41630421). J. Zhang is supported by the Fundamental Research Funds for the Central Universities (lzujbky-2017-4). We thank the scientific teams for NASA, ECMWF, NOAA PSD, CRU and Hadley Centre data. We would thank NCAR for providing the WACCM3 model. The SLIMCAT modelling work was supported by the UK National Centre for Atmospheric Science (NCAS). W. Feng would like to acknowledge the support of NCAS funds. Finally, the authors acknowledged the computing support provided by the College of Atmospheric Sciences, Lanzhou University.

Open Access This article is distributed under the terms of the Creative Commons Attribution 4.0 International License (http://creativeco mmons.org/licenses/by/4.0/), which permits unrestricted use, distribution, and reproduction in any medium, provided you give appropriate credit to the original author(s) and the source, provide a link to the Creative Commons license, and indicate if changes were made.

\section{References}

Allen RJ, Zender CS (2011) The role of eastern Siberian snow and soil moisture anomalies in quasi-biennial persistence of the Arctic and North Atlantic Oscillations. J Geophys Res Atmos. https://doi. org/10.1029/2010jd015311

Ambaum MH, Hoskins BJ (2002) The NAO troposphere-stratosphere connection. J Clim 15(14):1969-1978

Angell JK, Free M (2009) Ground-based observations of the slowdown in ozone decline and onset of ozone increase. J Geophys Res Atmos. https://doi.org/10.1029/2008jd010860

Bodeker GE, Shiona H, Eskes H (2005) Indicators of Antarctic ozone depletion. Atmos Chem Phys 5:2603-2615

Cagnazzo C, Claud C, Hare S (2006) Aspects of stratospheric longterm changes induced by ozone depletion. Clim Dyn 27(1):101111. https://doi.org/10.1007/s00382-006-0120-1

Calisesi Y, Wernli H, Kämpfer N (2001) Midstratospheric ozone variability over Bern related to planetary wave activity during the winters 1994-1995 to 1998-1999. J Geophys Res Atmos 106:7903-7916. https://doi.org/10.1029/2000JD900710

Callis LB, Natarajan M, Lambeth JD, Boughner RE (1997) On the origin of midlatitude ozone changes: data analysis and simulations for 1979-1993. J Geophys Res Atmos 102:1215-1228 doi. https ://doi.org/10.1029/96jd03058

Chipperfield MP (2006) New version of the TOMCAT/SLIMCAT offline chemical transport model: Intercomparison of stratospheric tracer experiments. Q J Roy Meteorol Soc 132:1179-1203

Chipperfield MP et al (2017) Detecting recovery of the stratospheric ozone layer. Nature 549:211-218

Cionni I et al (2011) Ozone database in support of CMIP5 simulations: results and corresponding radiative forcing. Atmos Chem Phys 11:11267-11292. https://doi.org/10.5194/acp-11-11267-2011

Cohen JL, Furtado JC, Barlow M, Alexeev VA, Cherry JE (2012) Asymmetric seasonal temperature trends. Geophys Res Lett. https ://doi.org/10.1029/2011g1050582

Crook JA, Gillett NP, Keeley SPE (2008) Sensitivity of Southern Hemisphere climate to zonal asymmetry in ozone. Geophys Res Lett. https://doi.org/10.1029/2007gl032698

Czaja A, Frankignoul C (2002) Observed impact of Atlantic SST anomalies on the North Atlantic oscillation. J Clim 15:606-623. https://doi.org/10.1175/1520-0442(2002)015\%3C0606:Oioas a\%3E2.0.Co;2

Dee DP et al (2011) The ERA-Interim reanalysis: configuration and performance of the data assimilation system. Q J R Meteorol Soc 137:553-597. https://doi.org/10.1002/qj.828

Dong B, Dai A (2015) The influence of the interdecadal Pacific oscillation on temperature and precipitation over the globe. Clim Dyn 45(9-10):2667-2681

Dragani R (2011) On the quality of the ERA-Interim ozone reanalyses: comparisons with satellite data. Q J R Meteorol Soc 137:1312-1326

Efstathiou MN, Varotsos CA, Singh RP, Cracknell AP, Tzanis C (2003) On the longitude dependence of total ozone trends over middlelatitudes. Int J Remote Sens 24:1361-1367

Eyring V et al (2006) Assessment of temperature, trace species, and ozone in chemistry-climate model simulations of the recent past. J Geophys Res Atmos. https://doi.org/10.1029/2006jd007327 
Eyring V et al (2010) Multi-model assessment of stratospheric ozone return dates and ozone recovery in CCMVal-2 models. Atmos Chem Phys 10:9451-9472. https://doi.org/10.5194/ acp-10-9451-2010

Feng W et al (2005) Three-dimensional model study of the Arctic ozone loss in 2002/2003 and comparison with 1999/2000 and 2003/2004. Atmos Chem Phys 5:139-152

Frossard L et al (2013) On the relationship between total ozone and atmospheric dynamics and chemistry at mid-latitudes-part 1 : statistical models and spatial fingerprints of atmospheric dynamics and chemistry. Atmos Chem Phys 13:147-164. https://doi. org/10.5194/acp-13-147-2013

Gabriel A, Peters D, Kirchner I, Graf HF (2007) Effect of zonally asymmetric ozone on stratospheric temperature and planetary wave propagation. Geophys Res Lett. https://doi.org/10.1029/2006g 1028998

Gabriel A, Kornich H, Lossow S, Peters DHW, Urban J, Murtagh D (2011) Zonal asymmetries in middle atmospheric ozone and water vapour derived from Odin satellite data 2001-2010. Atmos Chem Phys 11:9865-9885. https://doi.org/10.5194/acp-11-9865-2011

Gabriel A, Höschel I, Peters DHW, Kirchner I, Graf HF (2013) The influence of zonally asymmetric stratospheric ozone on the coupling of atmospheric layers. In: Lübken FJ (ed) Climate and weather of the sun-earth system (CAWSES). Springer, Dordrecht, pp 443-466. https://doi.org/10.1007/978-94-007-4348-9_24

Garcia RR, Marsh DR, Kinnison DE, Boville BA, Sassi F (2007) Simulation of secular trends in the middle atmosphere, 1950-2003. J Geophys Res. https://doi.org/10.1029/2006JD007485

Gillett NP, Scinocca JF, Plummer DA, Reader MC (2009) Sensitivity of climate to dynamically-consistent zonal asymmetries in ozone. Geophys Res Lett. https://doi.org/10.1029/2009g1037246

Gonzalez PL, Polvani LM, Seager R, Correa GJ (2014) Stratospheric ozone depletion: a key driver of recent precipitation trends in South Eastern South America. Clim Dyn 42(7-8):1775-1792

Grytsai AV, Grytsai Z, Evtushevsky AM, Milinevsky G, Leonov NA (2005) Zonal wave numbers $1-5$ in planetary waves from the TOMS total ozone at $65^{\circ} \mathrm{S}$. Ann Geophys Germany 23:1565-1573

Grytsai AV, Evtushevsky OM, Agapitov OV, Klekociuk AR, Milinevsky GP (2007) Structure and long-term change in the zonal asymmetry in Antarctic total ozone during spring. Ann Geophys Germany 25:361-374

Guo D, Su Y, Zhou X, Xu J, Shi C, Liu Y, Li W, Li Z (2017) Evaluation of the trend uncertainty in summer ozone valley over the Tibetan plateau in three reanalysis datasets. J Meteor Res 31(2):431-437

Hadjinicolaou P, Pyle JA, Harris NRP (2005) The recent turnaround in stratospheric ozone over northern middle latitudes: a dynamical modeling perspective. Geophys Res Lett. https://doi. org/10.1029/2005gl022476

Harris I, Jones PD, Osborn TJ, Lister DH (2014) Updated high-resolution grids of monthly climatic observations-the CRU TS3.10 Dataset. Int J Climatol 34:623-642. https://doi.org/10.1002/ joc. 3711

He Y, Huang J, Ji M (2014) Impact of land-sea thermal contrast on interdecadal variation in circulation and blocking. Clim Dyn 43:3267-3279

Hio Y, Yoden S (2004) Quasi-periodic variations of the polar vortex in the Southern Hemisphere stratosphere due to wave-wave interaction. J Atmos Sci 61:2510-2527

Hood LL, Soukharev BE (2005) Interannual variations of total ozone at northern midlatitudes correlated with stratospheric EP flux and potential vorticity. J Atmos Sci 62:3724-3740. https://doi. org/10.1175/Jas3559.1

Hood LL, Zaff DA (1995) Lower stratospheric stationary waves and the longitude dependence of ozone trends in winter. J Geophys Res Atmos 100:25791-25800. https://doi.org/10.1029/95jd01943
Hu JG, Li T, Xu HM, Yang SY (2017) Lessened response of boreal winter stratospheric polar vortex to El Niño in recent decades. Clim Dyn 49(1-2):263-278. https://doi.org/10.1007/s0038 2-016-3340-z

Ialongo I, Sofieva V, Kalakoski N, Tamminen J, Kyrola E (2012) Ozone zonal asymmetry and planetary wave characterization during Antarctic spring. Atmos Chem Phys 12:2603-2614. https://doi. org/10.5194/acp-12-2603-2012

James PM, Peters D, Waugh DW (2000) Very low ozone episodes due to polar vortex displacement. Tellus B 52:1123-1137. https://doi. org/10.1034/j.1600-0889.2000.00128.x

Janicot S, Trzaska S, Poccard I (2001) Summer Sahel-ENSO teleconnection and decadal time scale SST variations. Clim Dyn 18(3-4):303-320

Kirchner I, Peters D (2003) Modelling the wintertime response to upper tropospheric and lower stratospheric ozone anomalies over the North Atlantic and Europe. Ann Geophys 21:2107-2118. https:// doi.org/10.5194/angeo-21-2107-2003

Krzyścin JW (2010) Onset of the total ozone increase based on statistical analyses of global ground-based data for the period 19642008. Int J Climatol 32:240-246. https://doi.org/10.1002/joc.2264

Li YP, Tian WS, Xie F, Wen ZP, Zhang JK, Hu DZ, Han YY (2018) The connection between the second leading mode of the winter North Pacific sea surface temperature anomalies and stratospheric sudden warming events. Clim Dyn. https://doi.org/10.1007/s0038 2-017-3942-0

Limpasuvan V, Hartmann DL (2000) Wave-maintained annular modes of climate variability. J Clim 13:4414-4429

Linkin ME, Nigam S (2008) The north pacific oscillation-west Pacific teleconnection pattern: Mature-phase structure and winter impacts. J Clim 21:1979-1997. https://doi.org/10.1175/2007J CLI2048.1

Lu J, Greatbatch RJ, Peterson KA (2004) Trend in Northern Hemisphere winter atmospheric circulation during the last half of the twentieth century. J Clim 17(19):3745-3760

Mantua NJ, Hare SR, Zhang Y, Wallace JM, Francis RC (1997) A Pacific interdecadal climate oscillation with impacts on salmon production. B Am Meteorol Soc 78:1069-1079. https://doi. org/10.1175/1520-0477(1997)078\%3C1069:Apicow\%3E2.0.Co;2

McCormack JP, Nathan TR, Cordero EC (2011) The effect of zonally asymmetric ozone heating on the Northern Hemisphere winter polar stratosphere. Geophys Res Lett. https://doi. org/10.1029/2010GL045937

Müller R et al (2008) Simple measures of ozone depletion in the polar stratosphere. Atmos Chem Phys 8:251-264

Nathan TR, Cordero EC (2007) An ozone-modified refractive index for vertically propagating planetary waves. J Geophys Res Atmos. https://doi.org/10.1029/2006jd007357

Newchurch MJ, Yang ES, Cunnold DM, Reinsel GC, Zawodny JM, Russell JM (2003) Evidence for slowdown in stratospheric ozone loss: First stage of ozone recovery. J Geophys Res Atmos. https:// doi.org/10.1029/2003jd003471

Niu XF, Frederick JE, Stein ML, Tiao GC (1992) Trends in column ozone based on toms data-dependence on month, latitude, and longitude. J Geophys Res Atmos 97:14661-14669

Parker D, Folland C, Scaife A, Knight J, Colman A, Baines P, Dong B (2007) Decadal to multidecadal variability and the climate change background. J Geophys Res Atmos 112:D18

Peters D, Entzian G (1999) Longitude-dependent decadal changes of total ozone in boreal winter months during 197992. J Clim 12:1038-1048. https://doi.org/10.1175/15200442(1999)012\%3C1038:Lddcot\%3E2.0.Co;2

Peters D, Entzian G, Schmitz G (1996) Ozone anomalies over the North Atlantic European region during January 1979-1992-linear 
modelling of horizontal and vertical ozone transport by ultra-long waves. Beitr Phys Atmos 69(4):477-489

Peters DHW, Gabriel A, Entzian G (2008) Longitude-dependent decadal ozone changes and ozone trends in boreal winter months during 1960-2000. Ann Geophys 26:1275-1286. https://doi. org/10.5194/angeo-26-1275-2008

Peters DHW, Schneidereit A, Bügelmayer M, Zülicke C, Kirchner I (2015) Atmospheric circulation changes in response to an observed stratospheric zonal ozone anomaly. Atmos Ocean 53:74 88. https://doi.org/10.1080/07055900.2013.878833

Prather MJ (1986) Numerical advection by conservation of 2nd-order moments. J Geophys Res Atmos 91:6671-6681. https://doi. org/10.1029/Jd091id06p06671

Rayner NA et al (2003) Global analyses of sea surface temperature, sea ice, and night marine air temperature since the late nineteenth century. J Geophys Res Atmos. https://doi.org/10.1029/2002jd002670

Rienecker MM et al (2011) MERRA: NASA's modern-era retrospective analysis for research and applications. J Clim 24:3624-3648. https://doi.org/10.1175/JCLI-D-11-00015.1

Sassi F, Boville BA, Kinnison D, Garcia RR (2005) The effects of interactive ozone chemistry on simulations of the middle atmosphere. Geophys Res Lett. https://doi.org/10.1029/2004gl022131

Škerlak B, Sprenger M, Wernli H (2014) A global climatology of stratosphere-troposphere exchange using the ERA-Interim data set from 1979 to 2011. Atmos Chem Phys 14:913-937

Struthers H et al (2009) The simulation of the Antarctic ozone hole by chemistry-climate models. Atmos Chem Phys 9:6363-6376

Szopa S et al (2013) Aerosol and ozone changes as forcing for climate evolution between 1850 and 2100. Clim Dyn 40(9-10):2223-2250

Thompson DWJ, Wallace JM (1998) The Arctic Oscillation signature in the wintertime geopotential height and temperature fields. Geophys Res Lett 25:1297-1300. https://doi.org/10.1029/98g100950

Trenberth KE, Hurrell JW (1994) Decadal atmosphere-ocean variations in the pacific. Clim Dyn 9:303-319. https://doi.org/10.1007/ Bf00204745

Vigliarolo PK, Vera CS, Diaz SB (2005) Synoptic-scale variability and its relationship with total ozone and Antarctic vortex displacements. Mon Weather Rev 133:2374-2386. https://doi. org/10.1175/Mwr2977.1

Wallace JM, Zhang Y, Renwick JA (1995) Dynamic contribution to hemispheric mean temperature trends. Science 270:780-783. https ://doi.org/10.1126/science.270.5237.780

Wargan K et al (2018) Recent decline in extratropical lower stratospheric ozone attributed to circulation changes. Geophys Res Lett 45:5166-5176
Waugh DW, Oman L, Newman PA, Stolarski RS, Pawson S, Nielsen JE, Perlwitz J (2009) Effect of zonal asymmetries in stratospheric ozone on simulated Southern Hemisphere climate trends. Geophys Res Lett. https://doi.org/10.1029/2009g1040419

Wendler G, Chen L, Moore B (2014) Recent sea ice increase and temperature decrease in the Bering Sea area, Alaska. Theor Appl Climatol 117:393-398. https://doi.org/10.1007/s00704-013-1014-x

Wirth V (1993) Quasi-stationary planetary-waves in total ozone and their correlation with lower stratospheric temperature. J Geophys Res Atmos 98:8873-8882. https://doi.org/10.1029/92jd02820

WMO (World Meteorological Organization) (2011) Scientific assessment of ozone depletion: 2010, World Meteorological Organisation, Geneva, Switzerland Global Ozone Research and Monitoring Project-Report No. 52438

Wu QG, Straus DM (2004a) AO, COWL, and observed climate trends. J Clim 17:2139-2156. https://doi.org/10.1175/15200442(2004)017\%3C2139:Acaoct\%3E2.0.Co;2

Wu QG, Straus DM (2004b) On the existence of hemispherewide climate variations. J Geophys Res Atmos. https://doi. org/10.1029/2003jd004230

Xie F, Li J, Tian W, Fu Q, Jin F-F, Hu Y, Zhang J, Wang W, Sun C, Feng J, Yang Y, Ding R (2016) A connection from Arctic stratospheric ozone to El Niño-Southern oscillation. Environ Res Lett 11:124026

Xie F et al (2017) Variations in North Pacific sea surface temperature caused by Arctic stratospheric ozone anomalies. Environ Res Lett 12(11):114023

Yang E et al (2006) Attribution of recovery in lower-stratospheric ozone. J Geophys Res 111:D17309. https://doi.org/10.1029/2005J D006371

Zhang JK et al (2014) Climate warming and decreasing total column ozone over the Tibetan Plateau during winter and spring. Tellus B. https://doi.org/10.3402/Tellusb.V66.23415

Zhang JK, Tian WS, Wang ZW, Xie F, Wang FY (2015) The influence of ENSO on Northern Midlatitude Ozone during the winter to spring transition. J Clim 28:4774-4793. https://doi.org/10.1175/ Jcli-D-14-00615.1

Zhang JK, Tian W, Chipperfield MP, Xie F, Huang J (2016) Persistent shift of the Arctic polar vortex towards the Eurasian continent in recent decades. Nat Clim Change 6:1094-1099

Zhang JK et al (2018) Stratospheric ozone loss over the Eurasian continent induced by the polar vortex shift. Nat Commun 9(1):206

Zhou X, Li JP, Xie F, Ding RQ, Li YJ, Zhao S, Zhang JK, Li Y (2017) The effects of the Indo-Pacific warm pool on the stratosphere. Clim Dyn. https://doi.org/10.1007/s00382-017-3584-2 